\title{
Research Paper \\ Investigation and Evaluation of the Basic Islamic-Iranian Model of Progress
}

\author{
*Mohamad Nasr Esfahani' ${ }^{1}$, Gholamali Masuminia $^{1}$, Rahele Montazer ${ }^{1}$
}

1. Department of Islamic Economics and Banking, Faculty of Economics, Kharazmi University, Tehran, Iran.

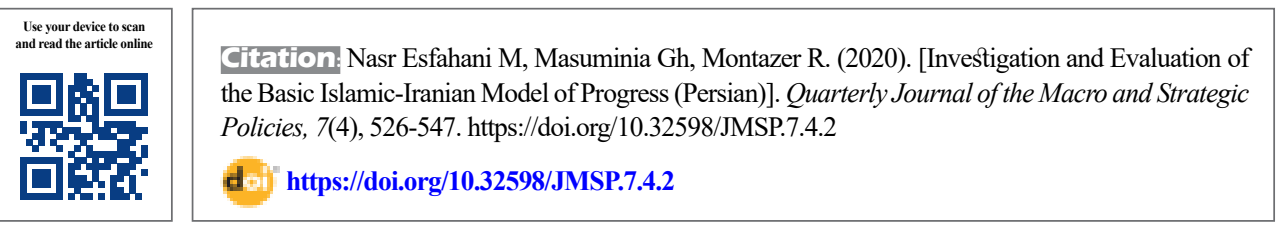

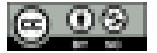

Received: 08 May 2019

Accepted: 28 Dec 2019

Available Online: 01 Jan 202

Key words:

Basic Islamic-Iranian model of progress, Statement by supreme leader, Critical analaysis

\begin{abstract}
This research was done after releasing According to the fifth item ofthe statement by supreme leader which was released after the of "publication of the basic Islamic-Iranian Model of Progress document" that in its fifth article has requested that was requested from universities, hawzah religious centers, and researchers scholars to evaluate this document deeply and participate in its promotion by presenting clear proposals of this document to plat plan a road map of country progress, by presenting clear proposals. This research has been done to respond to the above-mentioned request . In this article, we first review critiques of on the mistakes made before the process of document compilation and then critiques of on the mistakes made during the result and itscompilation, execution, and feasibility of the Model. The resultsinvestigation showed that at least 49 mistakes had been made during the compilation and preparation of the Model in three stages. in three sections: at first shortcomings and defects in the pre-codification of the model, second the errors and the ongoing errors in the pattern and pattern of the model, and third the feasibility of implementing of the model. The result of the survey shows that at least forty-nine defects, errors in the three above-mentioned stages in preparation of Process model. Therefore, it seems that the published document still needs to be worked on and its realization will not be simply feasible, and. So it is necessary to eliminate its shortcomings and defects to correct and complete the Model during the two-year's time left with the help of the elites and intellectualsto consider it during the two-year's time which has given to eliminate the shortcomings and defects to correct and complete the model with the help of the elites and intellectuals.

JEL Classification: O10, O21, 053
\end{abstract}

\section{* Corresponding Author: \\ Mohamad Nasr Esfahani}

Address: Department of Islamic Economics and Banking, Faculty of Economics, Kharazmi University, Tehran, Iran.

Tel: +98 (912) 1114172

E-mail: mnasr121@gmail.com 


\section{بررسى و ارزيابى التَوى هايه اسلامى ايرانى ييشرفت}

"محمد نصر اصفهانى' '، غلامعلى معصومىنيا'، راحله منتظر'

ا. دانشياره مدير كروه اقتصاد و بانكدارى اسلامى، دائشكده اقتصاد، دانشكاه خوارزمى، تهران، ايران.

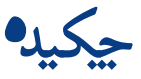

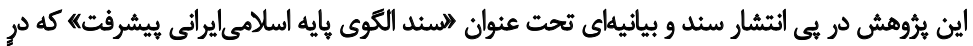

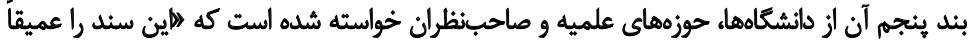

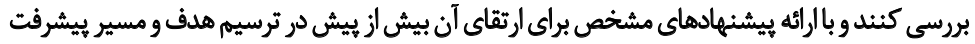

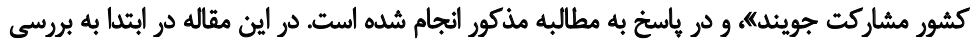

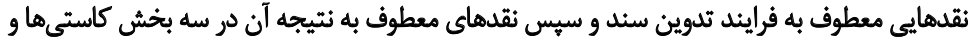

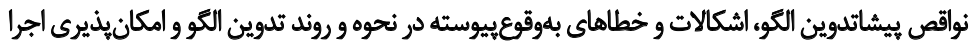

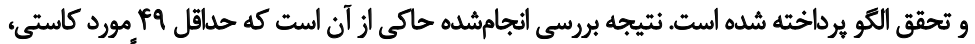

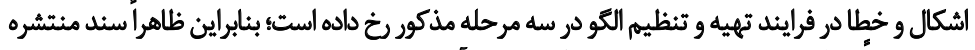

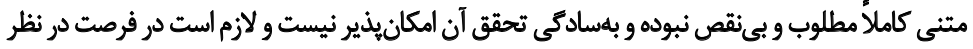

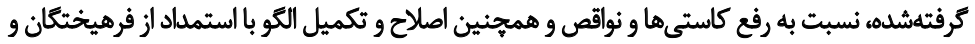
نخبعان اقدام شود.

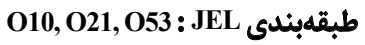

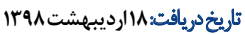
تاريخ يذيرش: ••دى

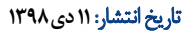

كليدوالرها: الأوى اسلامي ايراني

بيشرفت، بيانيه مقام هعظم رهبري، ديثرئ سيند، تحليل انتّقادى معظى نَخبحانى تحلى

* نويسنده مسئول:

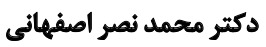

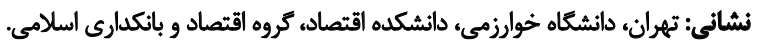

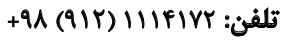
بست الكترونيكي: masr121@gmail.com 


\section{$\operatorname{Las}$}

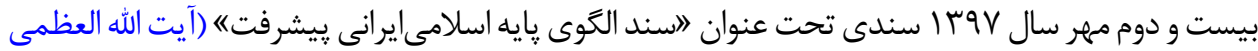

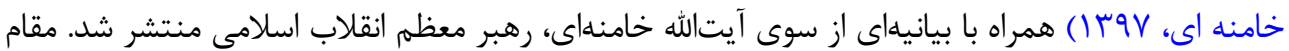

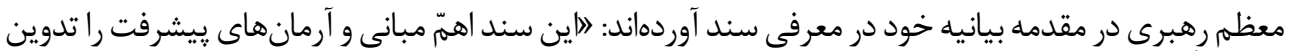

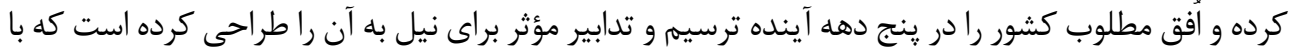

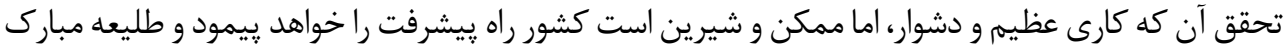

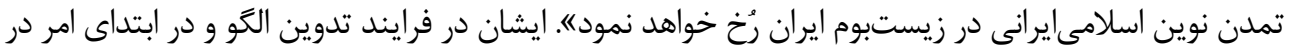

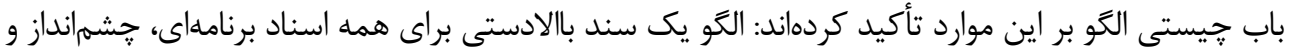

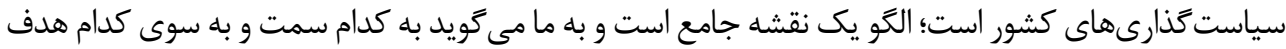

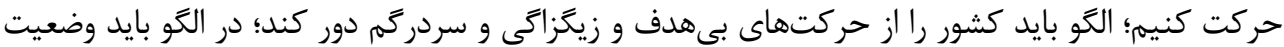

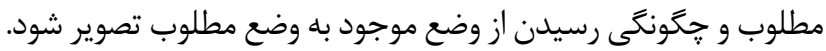

بر همين مبنا و برداشتى كه اعضاى شوراى عالى مركز الكوى اسلامىايرانى ييشرفت از منويات و بيانات مقام

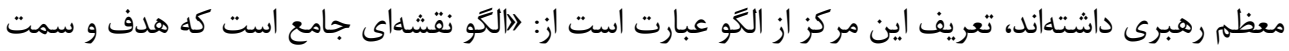

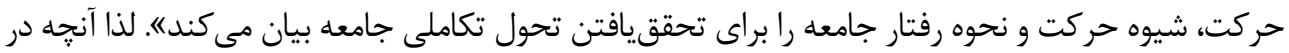

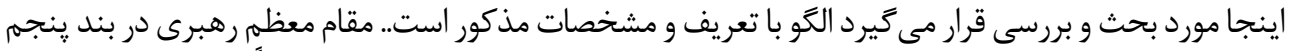

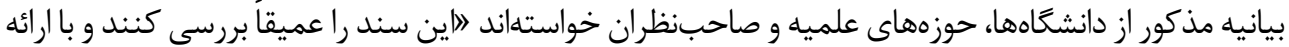

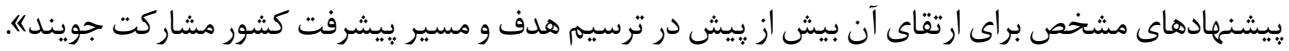

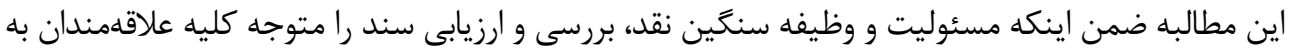

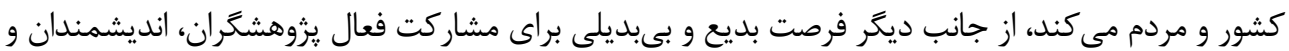

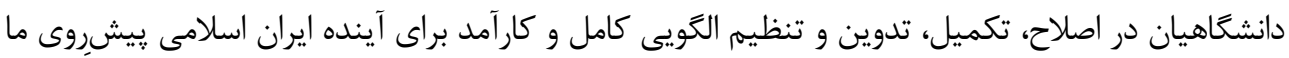

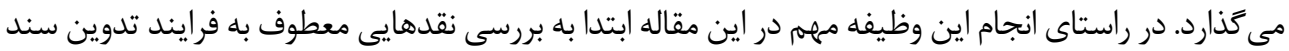

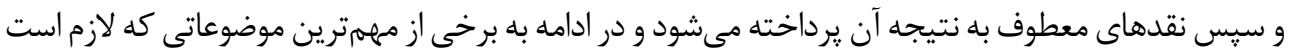

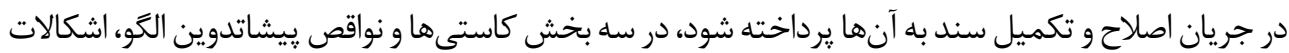

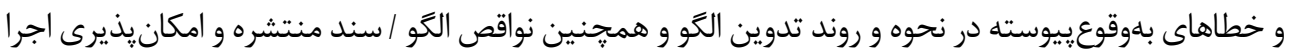

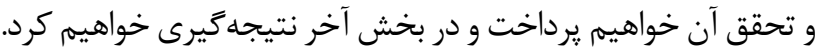

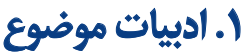

با رويكرد ارزيابى الكو، دو برداشت مختلف يا تقسيمبندى كلى از الگو در اين مقاله قابل ارائه است كه در اينجا

$$
\text { به تشريح آنها مى بيردازيم. }
$$

الف) الكوى فرايندى: الكوهاى فرايندى الكوهايى هستند كه مراحل فرايند رسيدن به نتيجه را نشان مى ردهند.

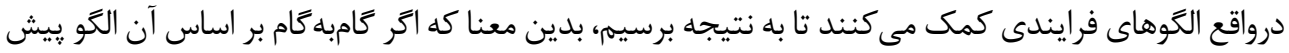


ب) الكوى نتيجهاى: اين دسته از الكوها در موضوعى مشخص مجموعه نتايج و راهكارهايى را به ما ارائه

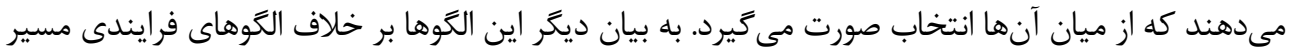

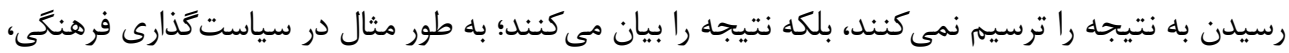

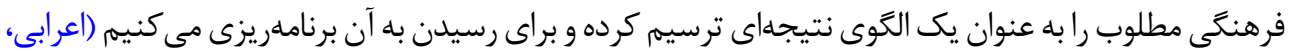

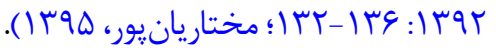

در اين مقاله، هنگامى كه از روش تهيه الخو و ارزيابى آن سخن مي گويم مفهوم، مدنظر از الخو، فرايندى است

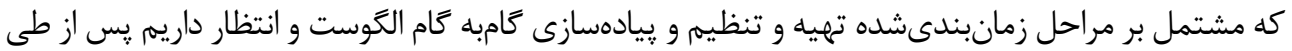

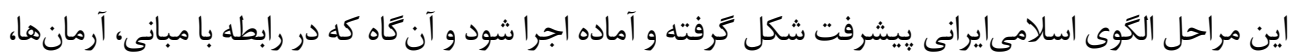

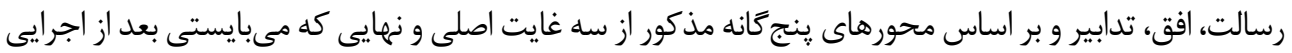

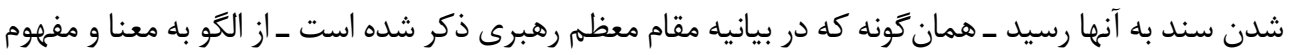

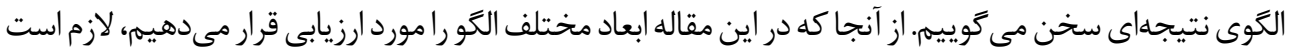

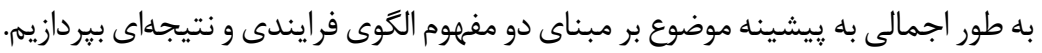

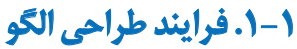

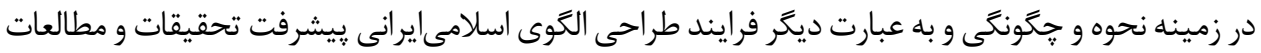

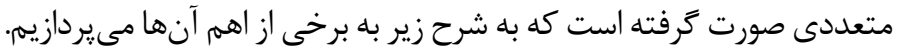

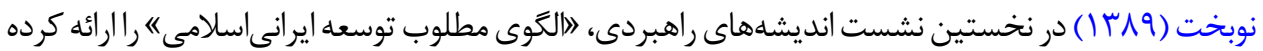

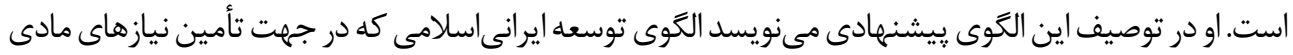

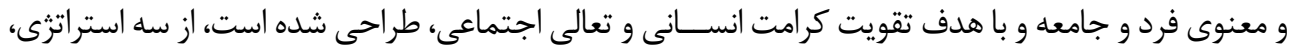

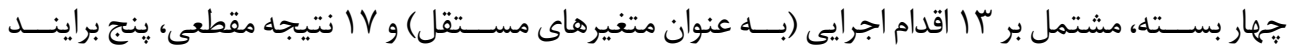

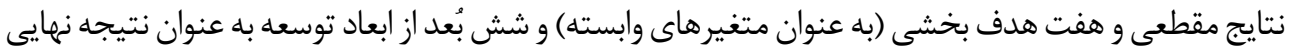

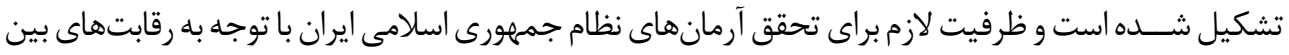

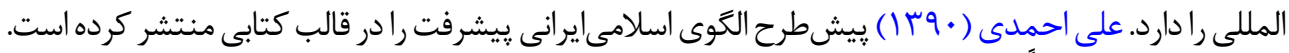

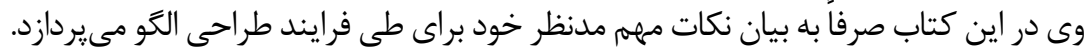

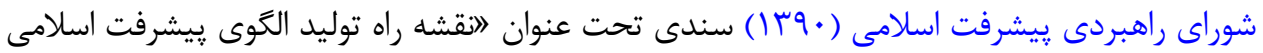

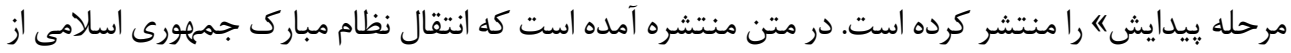

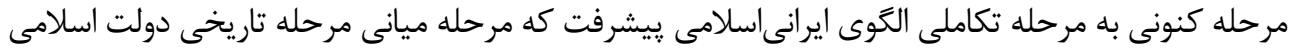

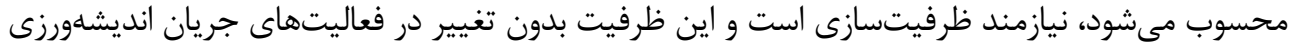

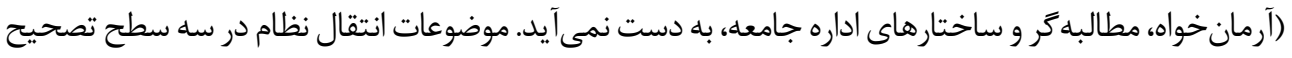

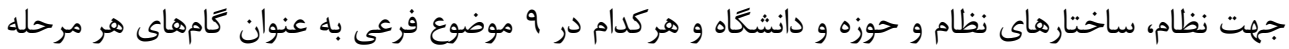




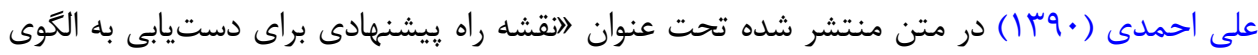

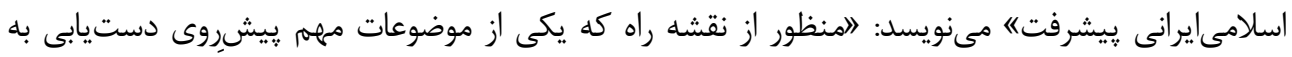

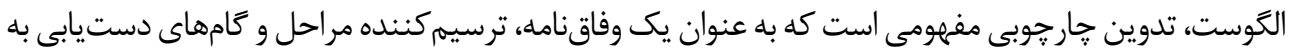

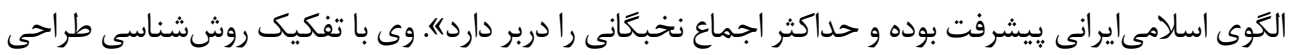

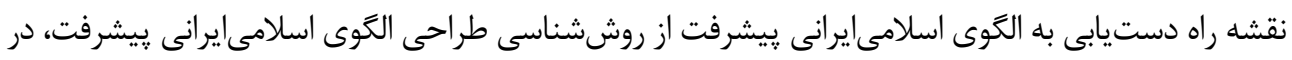

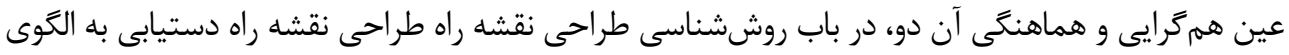

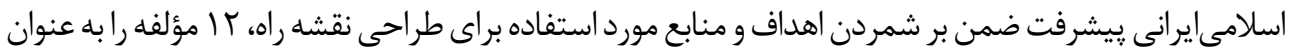

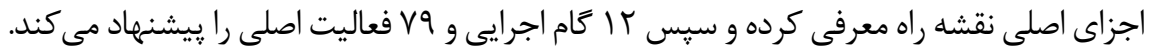

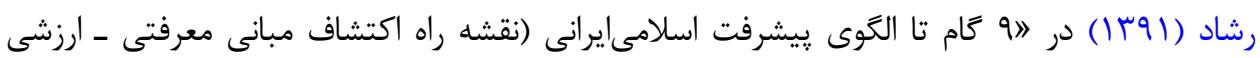
ييشرفتورزى و طراحى الكوى اسلامىايرانى ييشرفت)ه، هشت گام نظرى براى اكتشاف منطق اكتشاف نظريه

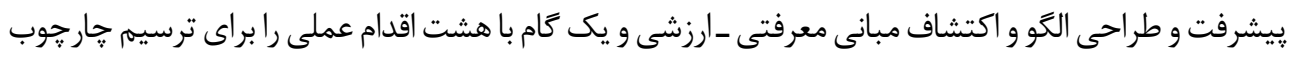

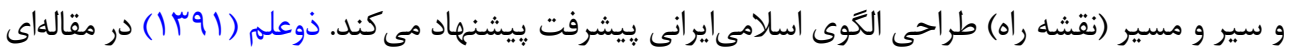

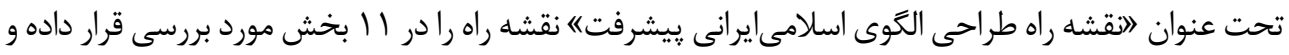

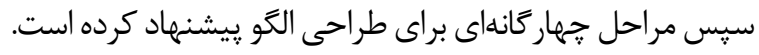

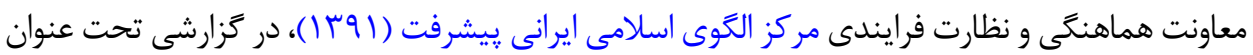

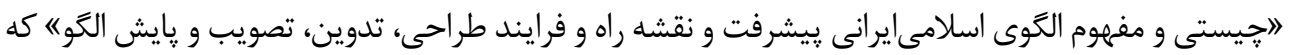

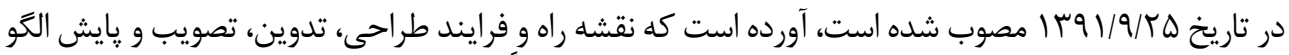

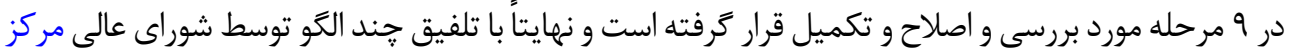

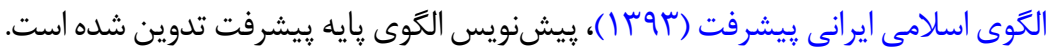

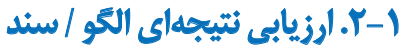

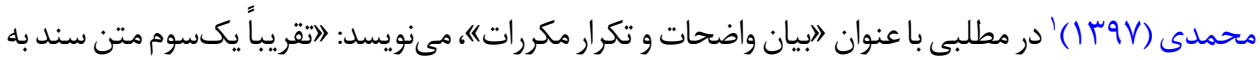

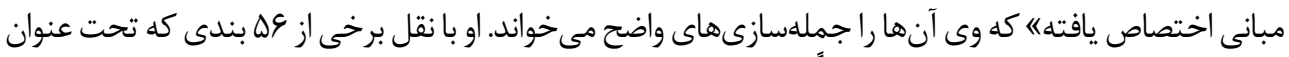

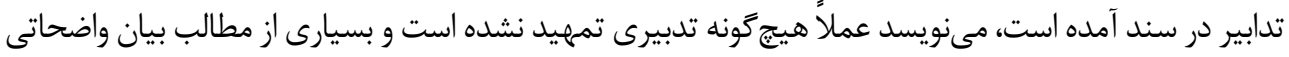

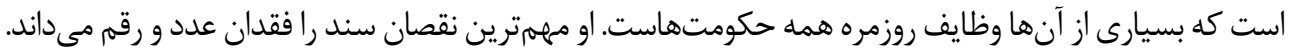

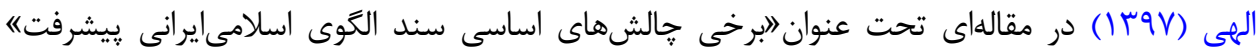

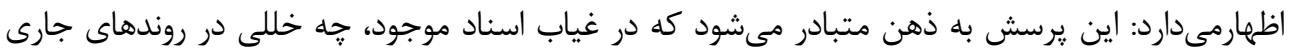

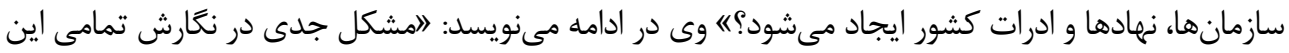




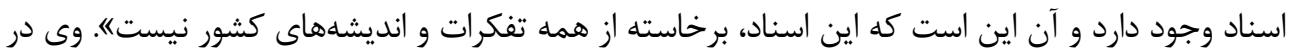

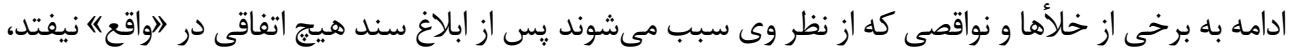

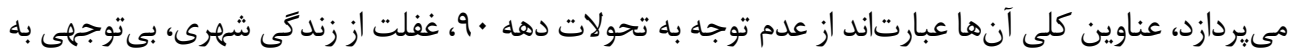
نقش هنر و عدم بيان نقش حوزه و و دانشعاه.

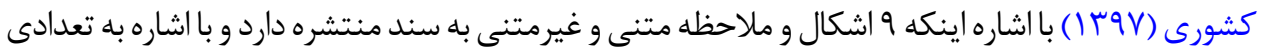

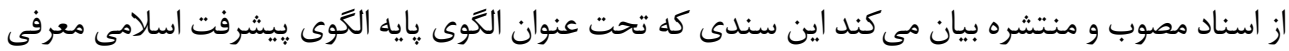

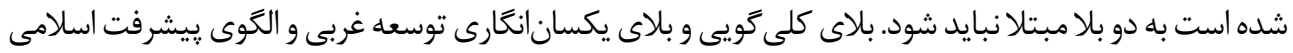

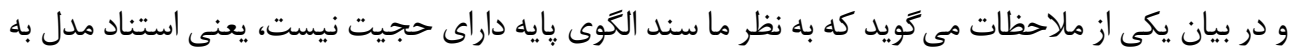

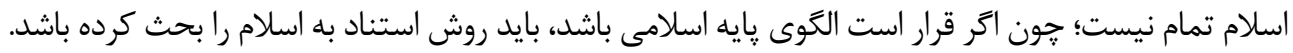

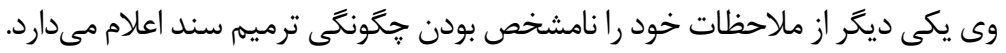

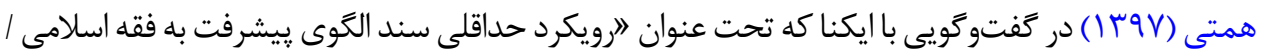

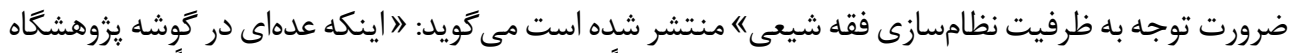

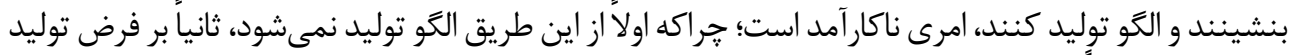

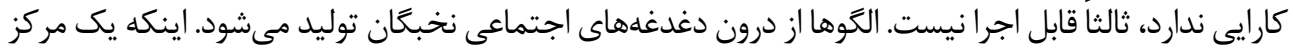

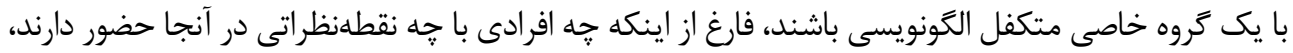

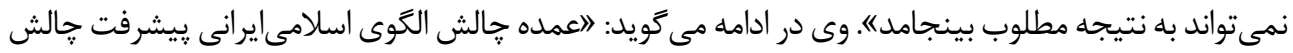

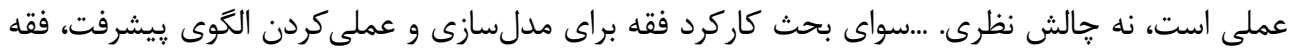

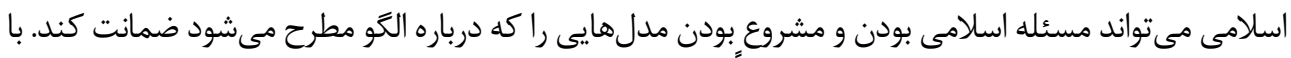

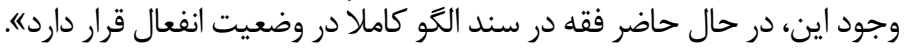

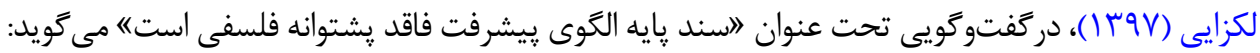

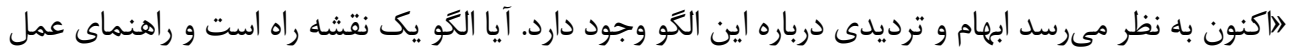

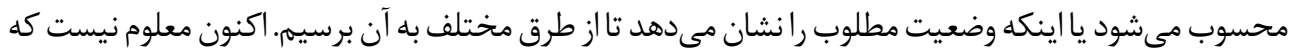

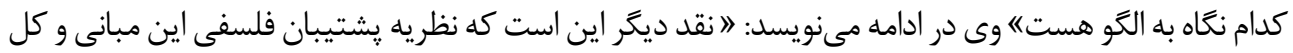

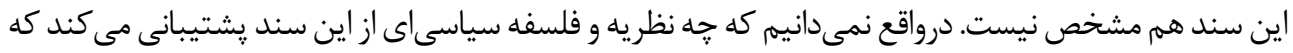

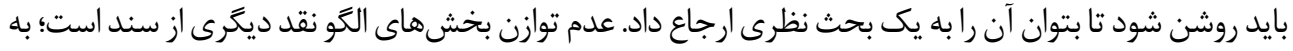

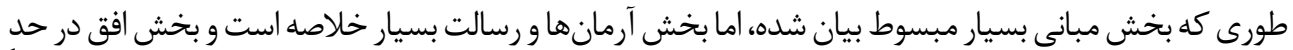

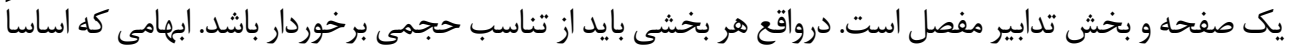

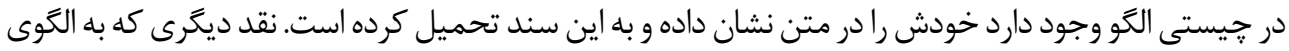

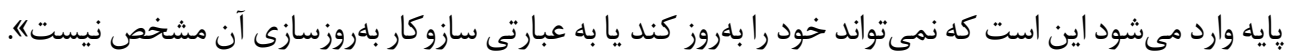

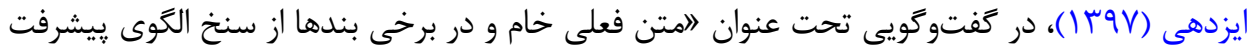

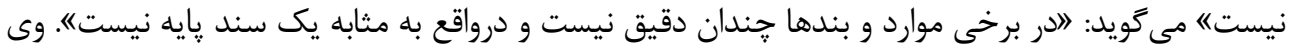




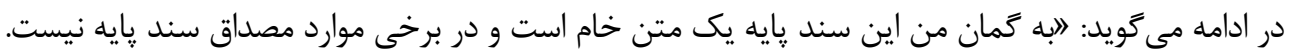

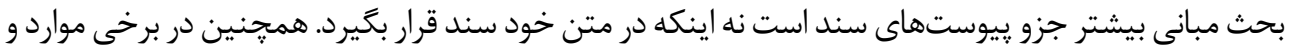

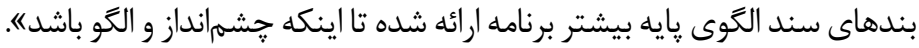

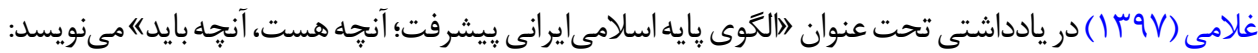

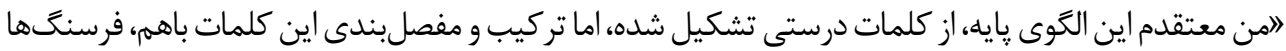

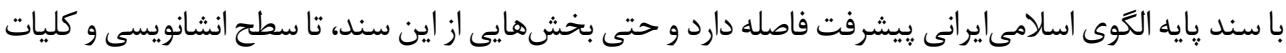

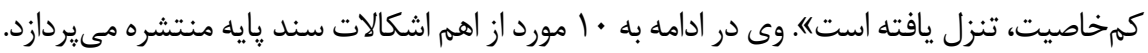

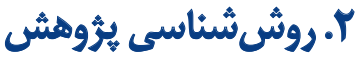

روش تحقيق ما در اين مقاله، توصيفى ـ تحليلى و بر بايه مطالعات اسنادى، كتابخانهاى و مجانلات معتبر

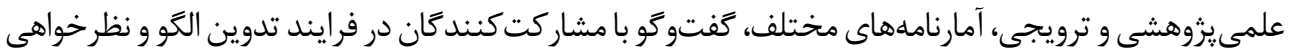

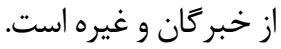

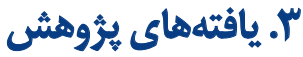

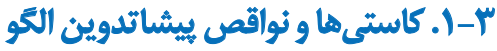

الف) آيا الكو تدوين كردنى است و اساساً مىتوان الكو تدوين كرد؟ به عبارت ديخر الكو نقشه عملى است يا

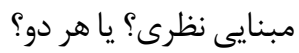

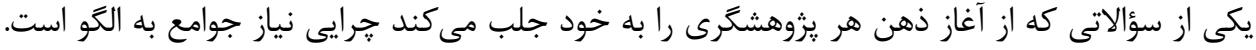

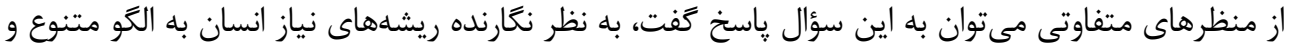

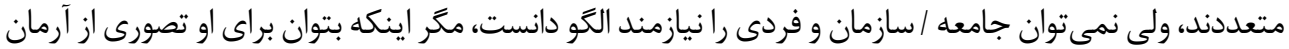

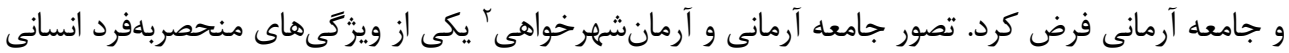

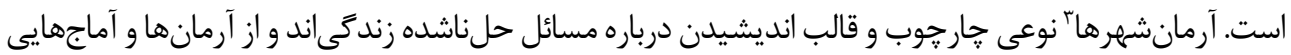

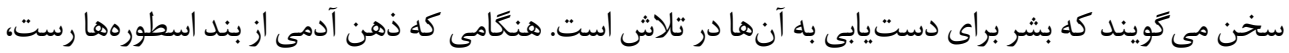

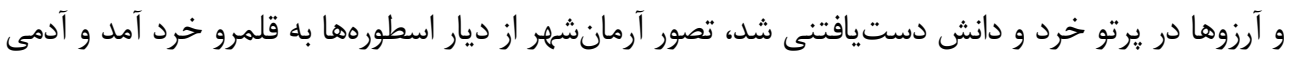

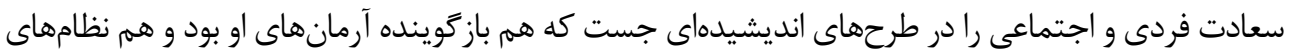

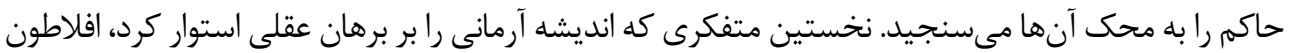

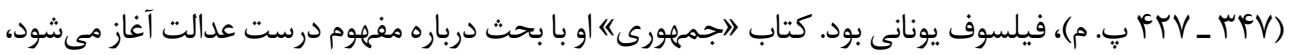

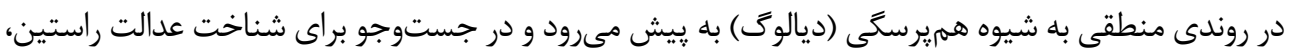

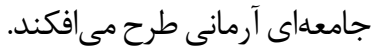

2. Utopianism.

3. Utopia. 
آرمانشهرها بازتاب شرايط عينى جامعهاند. نويسنده يا طراح آرمانشهر كه از اوضاع سياسى، اجتماعى و

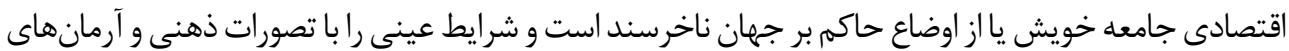

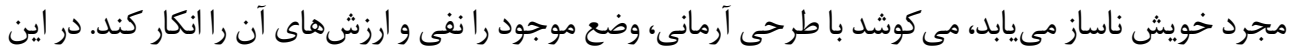

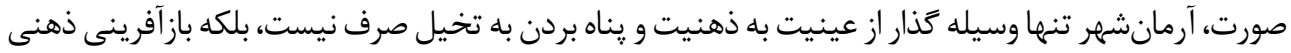

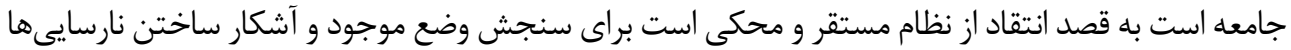

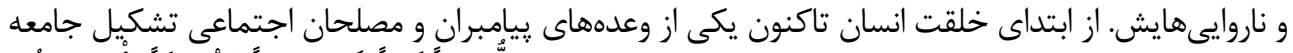

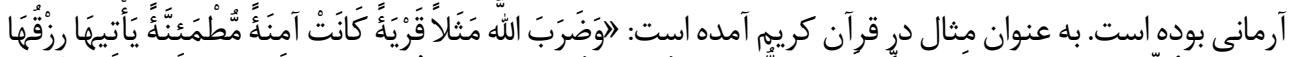

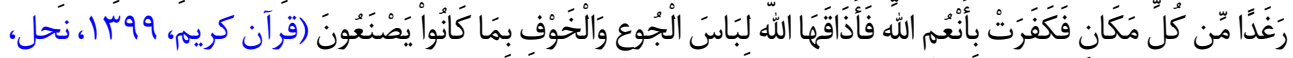

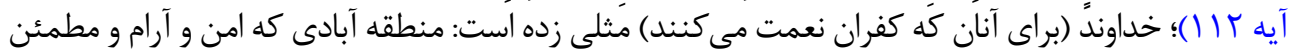

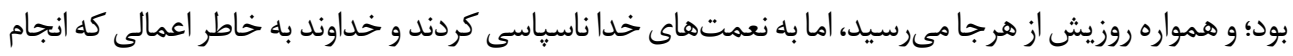

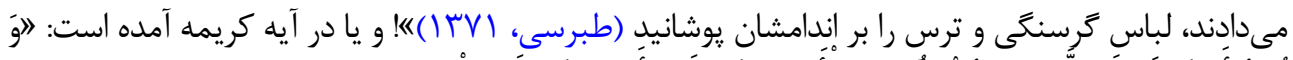

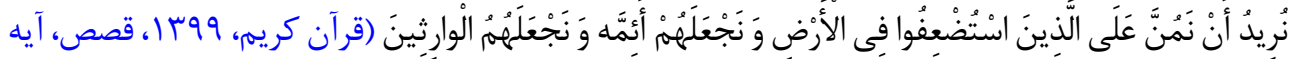

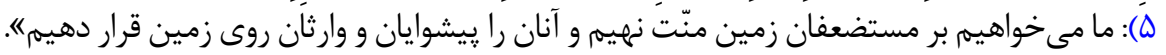
در دوران كوتاممدت حكومت اميرمؤمنان على (ع) نهتنها خبرى از غنايم هنَفت جنكى همانند زمان حاكمان

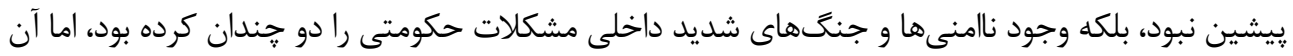

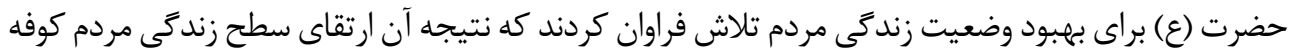

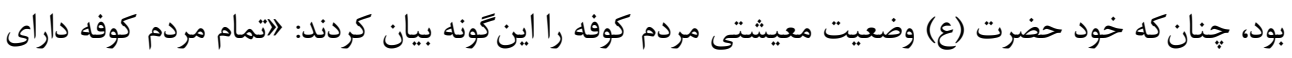

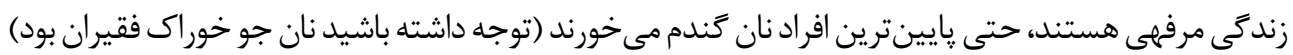

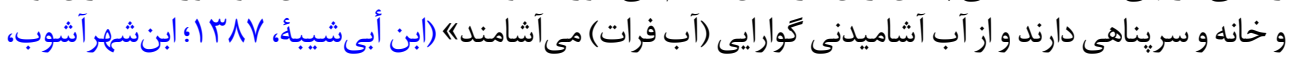

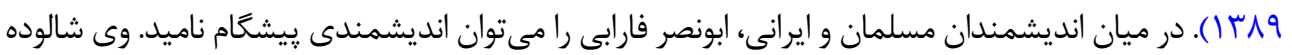

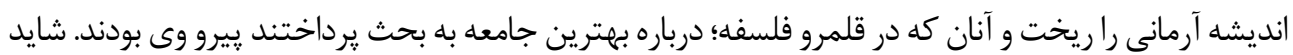

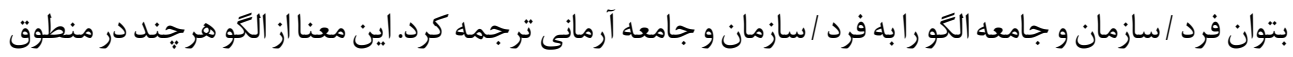

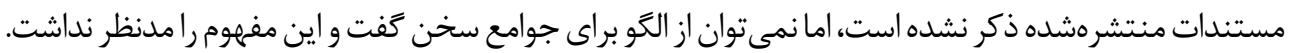

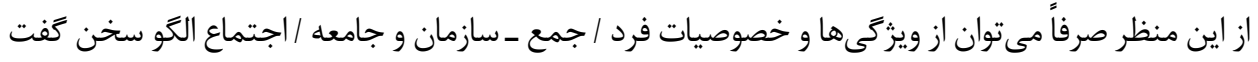

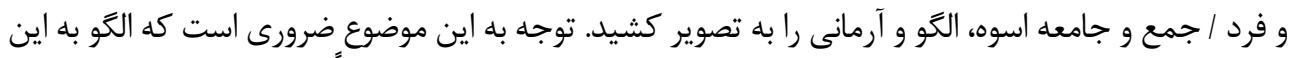

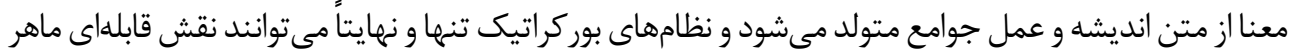

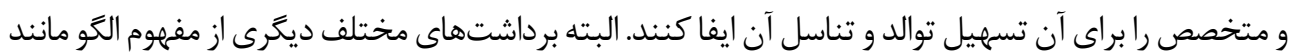

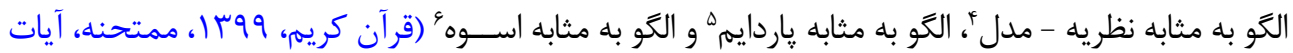

4. Model Theory.

5. Paradigm. 


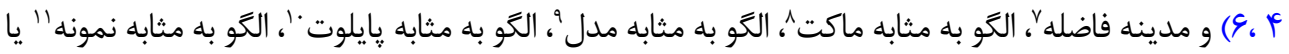

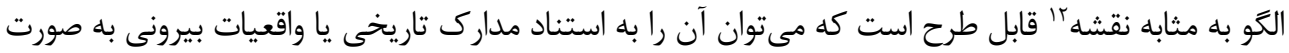

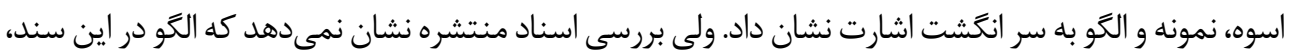

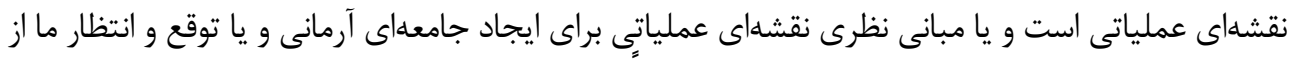

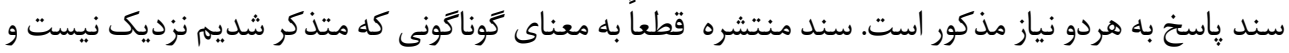

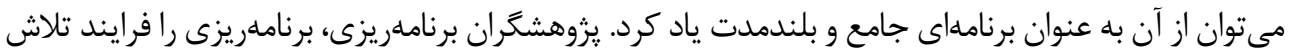

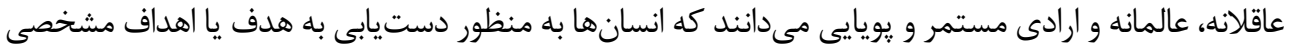

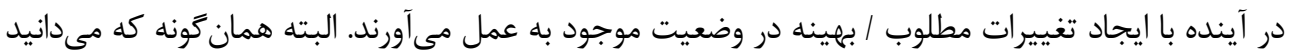

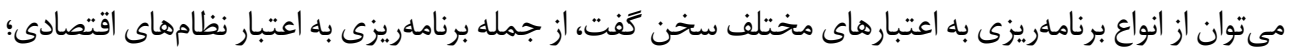

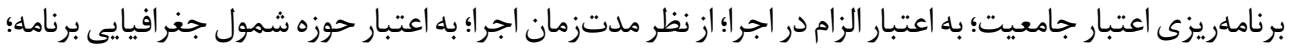

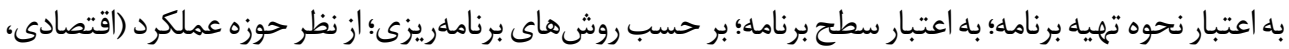

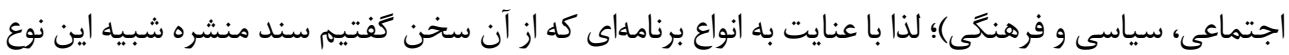

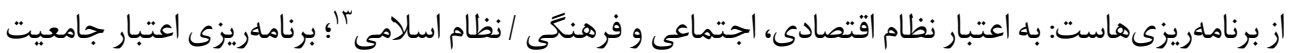

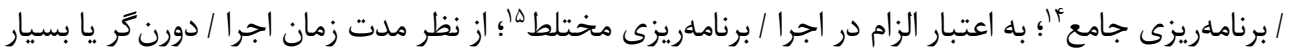

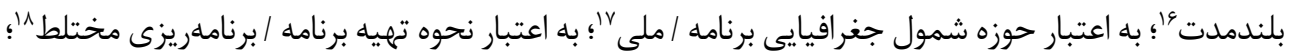

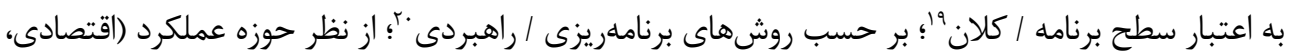

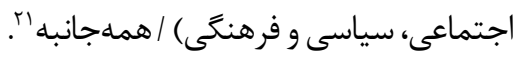

ب) آرادعا اين است كه اين الكو مبناى انديشه و عمل ايرانى در نيمقرن بعدى است، اين ادعا مبتنى بر جهه

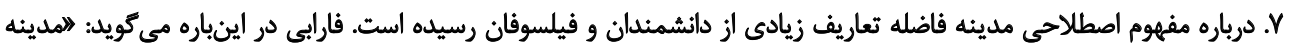

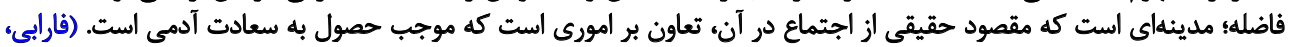

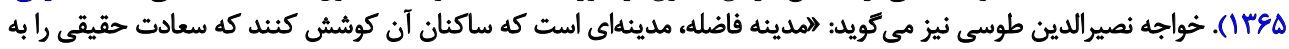

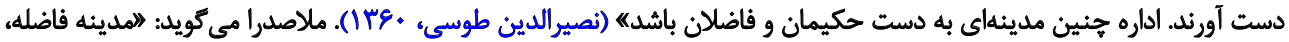

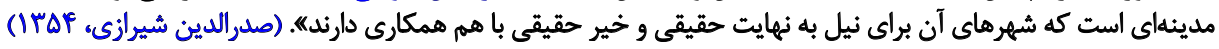
8. Maquette.

9. Model.

10. Pilot.

11. Pattern.

12. Map

13. Islamic System.

14. Comprehensive Planning.

15. Complex Planning.

16. Very long run / Perspective Planning.

17. National Planning.

18. Non Indicative \& Non Imperative Planning/Complex Planning.

19. Macroeconomic Planning.

20. Strategic Planning.

21. General Planning. 
به هر معنايى كه از الكو قائل باشيم، بدون تحليل صحيح و كامل وضع موجود، نه ما، بلكه هيج جامعهاى

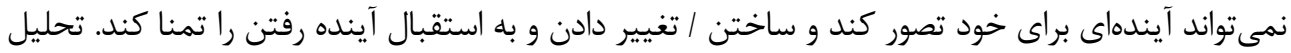

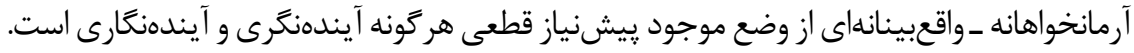

$$
\text { ج) جه كسى / كسانى مى توانند الگو تدوين كنند؟ }
$$

يكى از مهرمترين موضوعات كه بارها مورد تأكيد حضرت امام (ره) و مقام معظم رهبرى بوده است، تحول

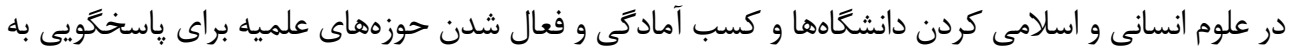

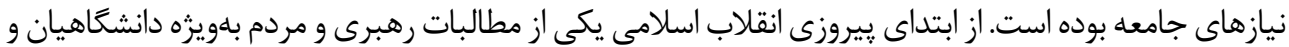

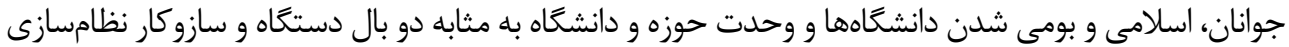

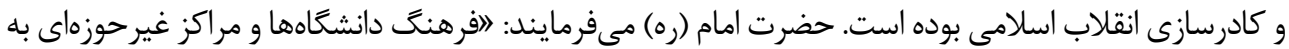

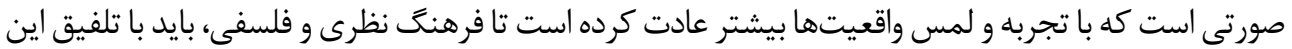

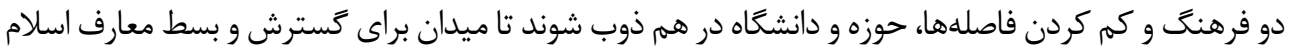

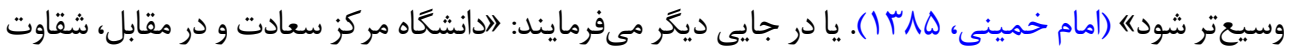

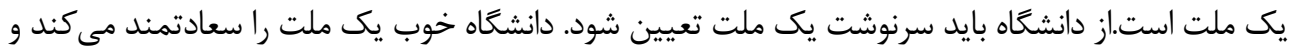

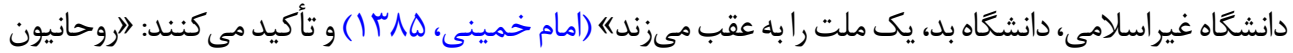

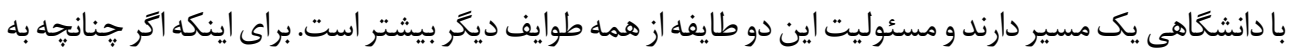

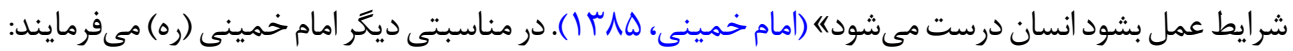

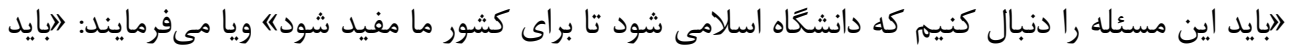

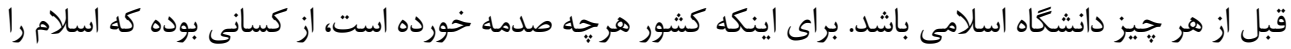

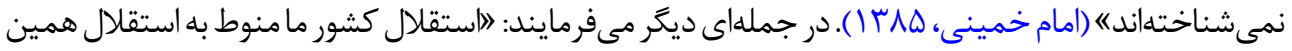

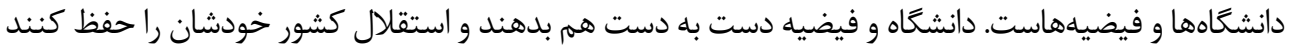

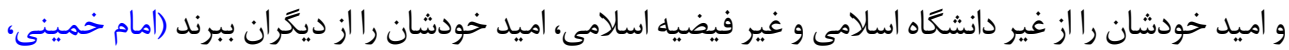

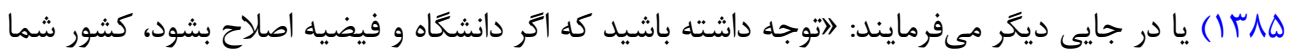

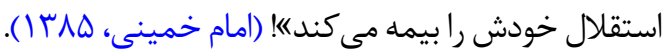

در همين زمينه و با بيانى ديگر مقام معظم رهبرى مىفرمايند: الحقيقتاً ما نيازمند آن هستيم كه يك تحول

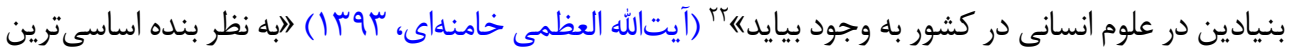

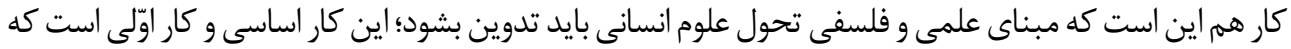

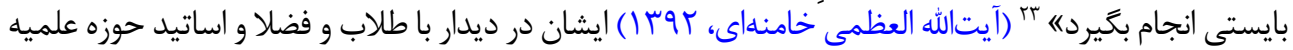

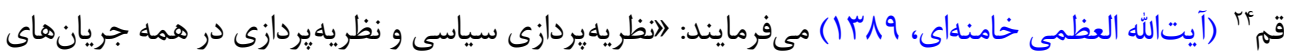


اداره يك ملت و يك كشور در نظام اسلامى به عهده علماى دين است. آن كسانى مى توانند در باب نظام اقتصادى،

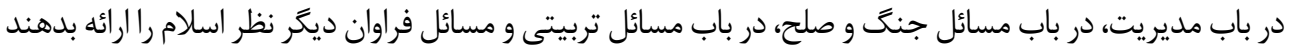

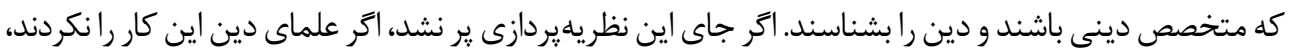

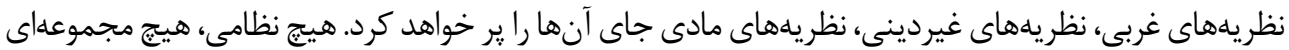

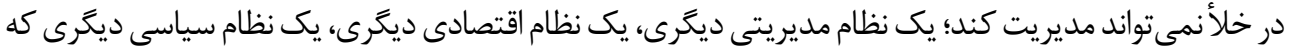

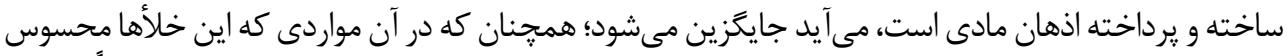

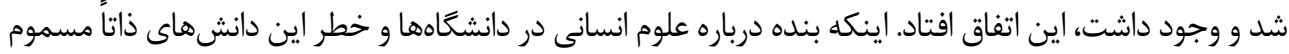

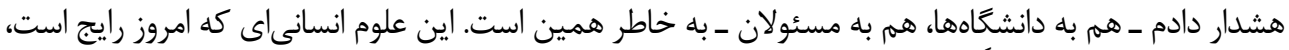

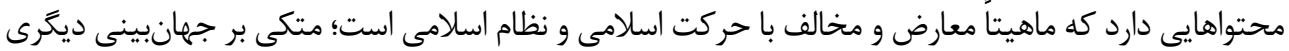

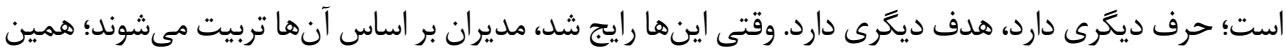

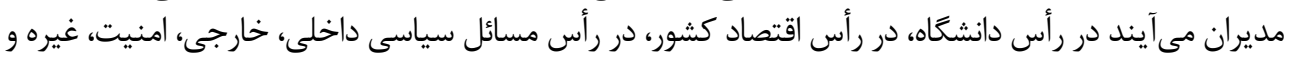

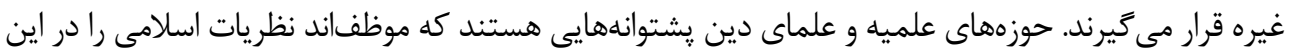

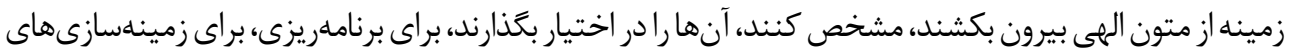

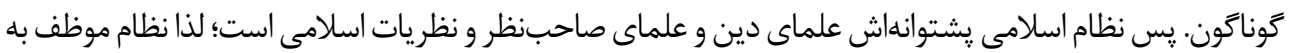

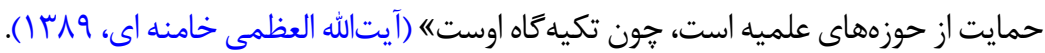

ايشان در حكم آغاز دوره جديد شوراى عالى انقلاب فرهنگى مى فرمايند: الموضوع تحول و نوسازى در نظام

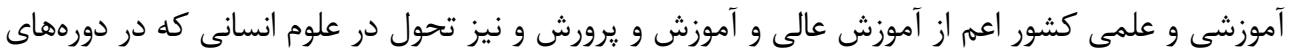

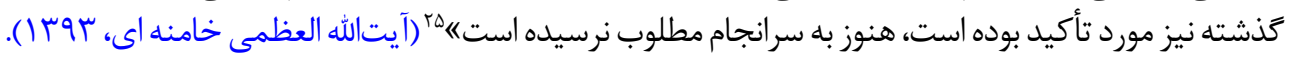
حال سؤال اساسى كه بايد بدان پاسخ دهيم اين است كه به فرض امكان يذيرى و مطلوبيت تهيه و تنظيم

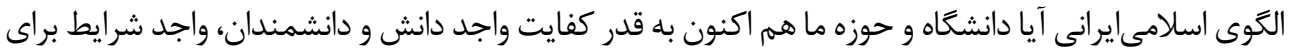

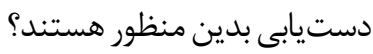

به بيان ديخر اخر ما تا كنون نتواستهايم علوم انسانى اسلامىايرانى و انديشمندان و دانشمندانى واجد آن را توليد

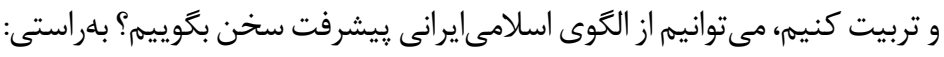
ذات نايافته از هستىبخش / جون تواند كه بود هستىبخش خشك ابرى كه بود ز آب تهى / نايد از وى صفت آبدهى (جامى، وعس ا) د) ارزيابى ما از برنامهها، سياستهاى كلى و سندهاى ييشين و در حال اجراو نسبت آنها با سند فعلى جيست همان گونه كه انديشمندان بارها تأكيد كردهاند و مقام معظه رهبرى نيزاشاره كردهاند: لاين ييوند با حذشته 


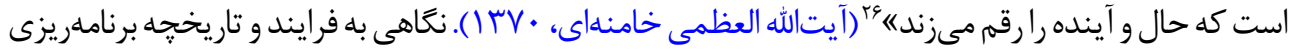

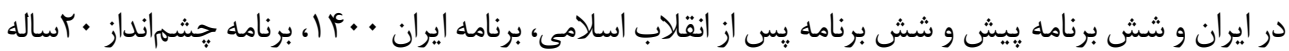

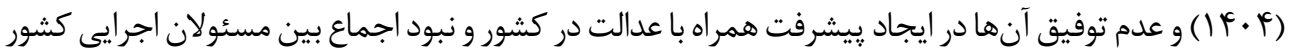

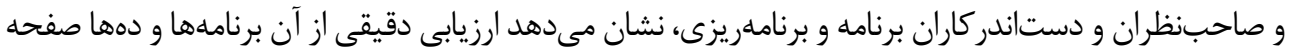

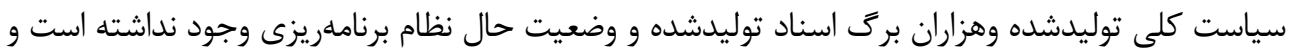

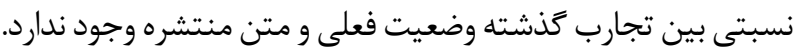
هـ) با توجه به تأكيد بر "روش علمى" روش تدوين الكو جيست و جهه تفاوتى با روش تدوين برنامهها،

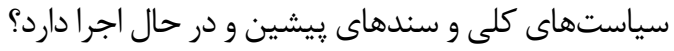

در متن سند منتشره ادعا شده است كه سند \... بر طبق روشهاى علمى و با استفاده از دستاوردهاى بشرى

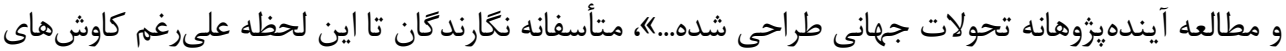

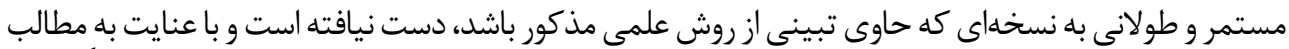

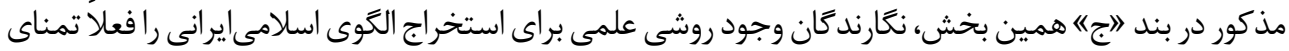

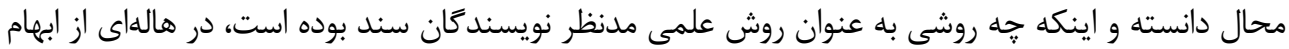

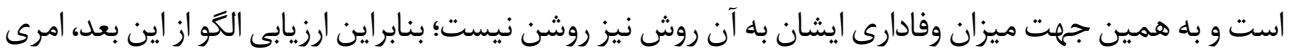
غير علمى خواهد بود.

و) نظريه جامع / فرانظريه / منظومه نظرى حاكم بر الگو جيست؟

صرفنظر از مواردى كه تاكنون يادآور شديم و با فرض اينكه كليه اشكالات ذكر شده و كاستىهاى مذكور

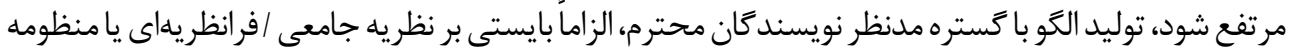

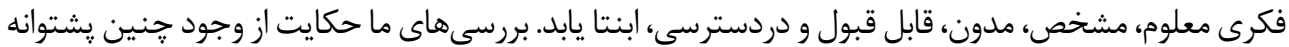

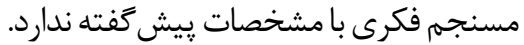

ز) اگر نظريه جامع / فرانظريه / منظومه نظرى وجود دارد، محصول كدام نظام نظريهيردازى است؟ صرفنظر از مواردى كه تاكنون يادآور شديم و با فرض اينكه نويسند معان به نظريه جامع، فرانظريه يا منظومه

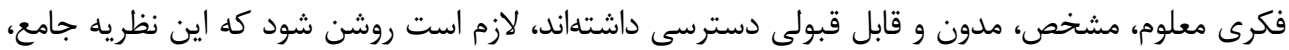

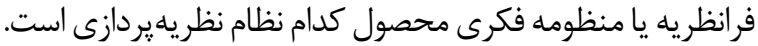
ح) آيندهنَارى براى نيممقرن جَگونه و با جه روشى انجام شده است؟

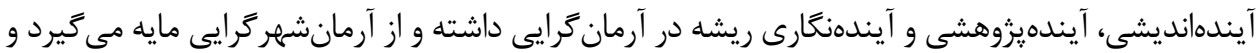

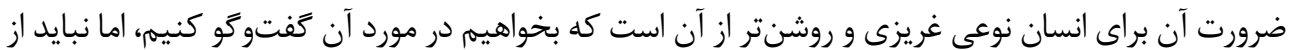

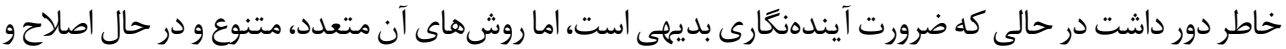


تكميل هستند و اين روشهاصرفاً تلاشهاى سازمانيافتهاى براى مقابله با محدوديتها و آسيبهاى آيندهنگرى

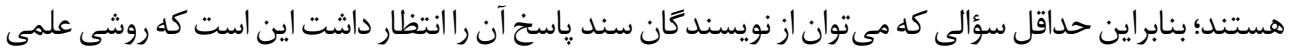

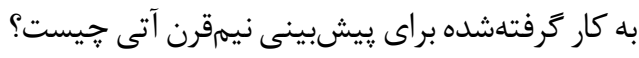

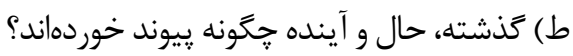
در صورتى كه سؤالات يِشين ياسخ درستى يابند، سؤال بعدى قابل طرح، اين است كه تبيين وضعيت كذشته

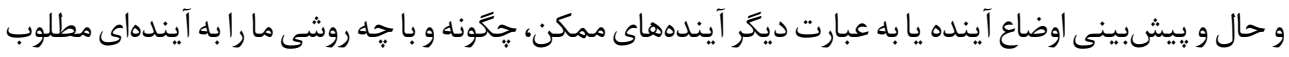
رهنمون مىشود؟

ى) فقدان فهم مشترك در سطح مفاهيم اوليهاى جون الخو / برنامه / مدل و توسعه / ي بيشرفت بين حوزه و

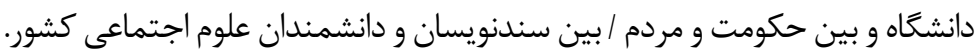

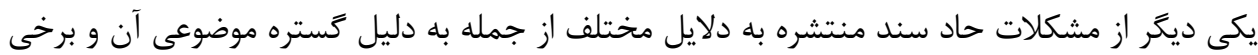

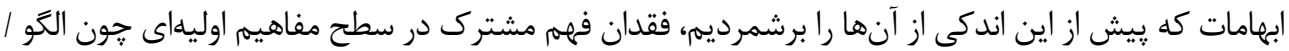

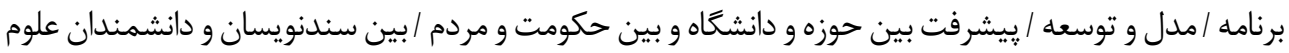

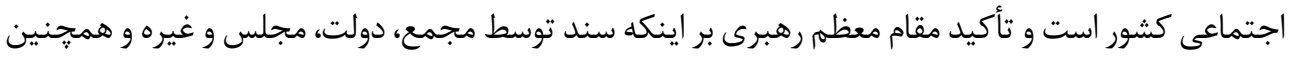

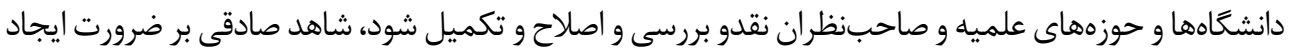
وفاق ملى حول سند است.

ك) عدم وجود اطلاعات و آمارهاى جامع، بهنغام و در دسترس. يكى از مشكلات تاريخى و مزمن تحليل وضعيت كذشته و حال و آيندهنگارى فقدان اطلاعات و آمارهاى

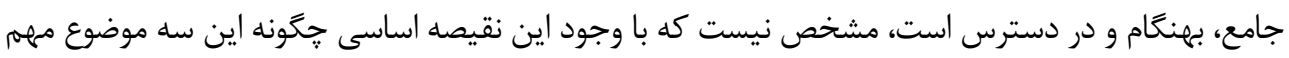
سامان يافته است. بعنمام دامت

$$
\text { ل) ساختار سياسى ـاجتماعى كشور }
$$

در كشورهايى برنامهريزى جامع و بلندمدت امكانيذير است كه ساختار سياسى ـ اجتماعى كشور آمادكى آنى

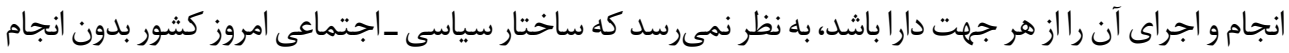

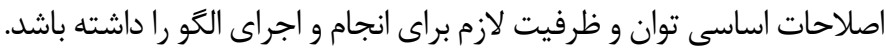

$$
\text { م) تمركزگرايى و نگاه بالا به يايين و دستورى بودن الخو }
$$

همان گونه كه ذكر شد، الكو برايند نظر و عمل جوامع و بلويزه اعتقاد، ارتباط وثيق و عميق فرهيختخان و

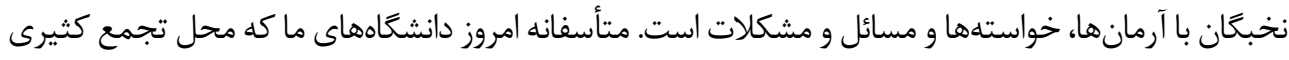

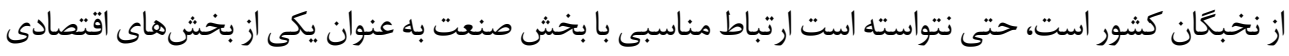
جامعه برقرار كند. 


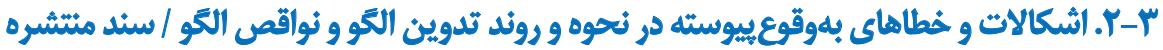

\section{الف) ارزيابى گذشته و تبينى ولو ناقص از وضع موجود ارائه نشده است.}

در مجموع اسناد منتشره در يايگاه اطلاعرسانى مركز اسلامىايرانى ييشرفت، هيج كونه تبيينى از وضع موجود

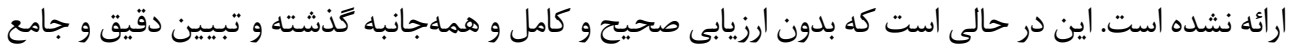

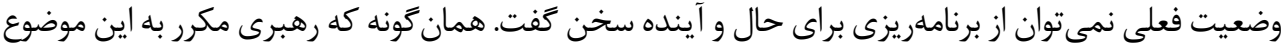

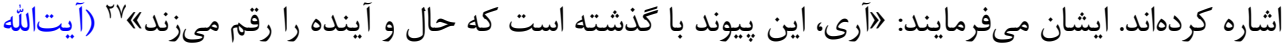

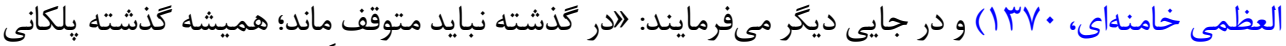

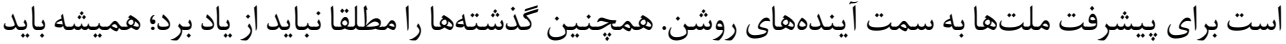

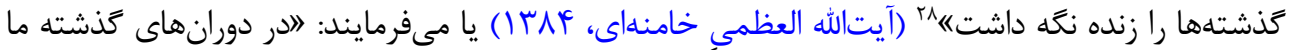

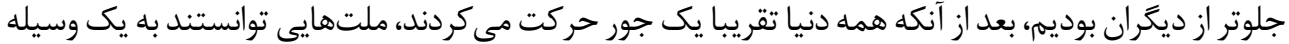

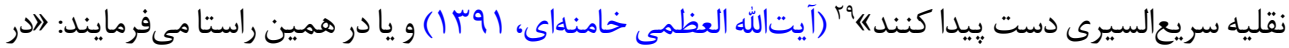

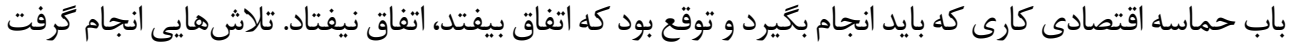

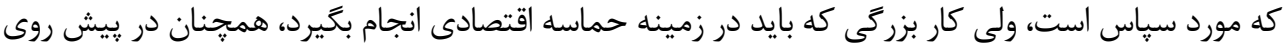

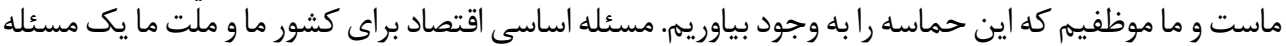

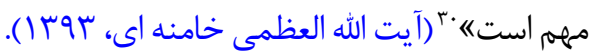

ب) وضع موجود و معنى آرى و عدم معنىدارى فاصله آن با الكو مشخص نشده است / وضع موجود آسيبشناسى نشده است.

صرفنظر از وجود يا عدم وجود ارزيابى صحيح و كامل و همهجانبه كذشته و تبيين دقيق و جامع وضعيت

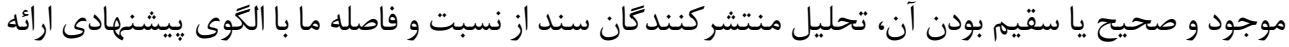
نشده است و آسيبشناسى وضع كذشته و حال جامعه هدف، از سوى تدوين كنند كان سند انجام نيذيرفته است. ج) نقشه راه و فرايند طراحى، تدوين، تصويب و يايش الكو، تلفيقى از حداقل دو نقشه راه با دو زمينه فكرى و

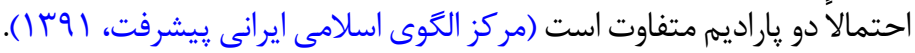

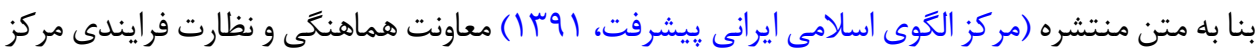

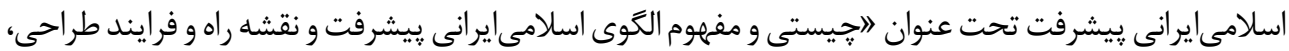

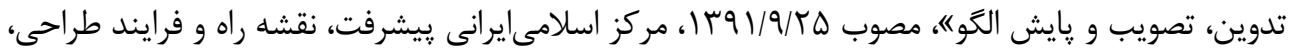

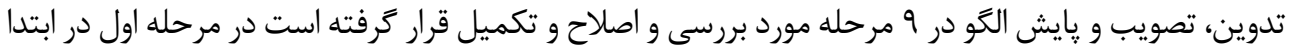


بهمن سال • و ا بر اساس ييشنهاد معاونت هماهنگى و نظارت فرايندى و موافقت رياست محترم مركز، كارگروه

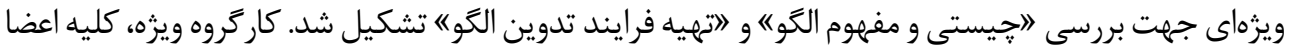

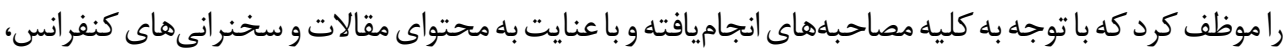

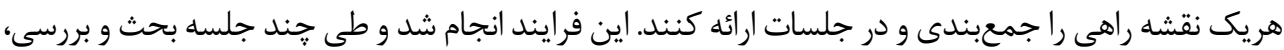
هريك از اعضاى كارگروه ويزه، نمودار استنتاجى خونى خود را ارائه كردند.

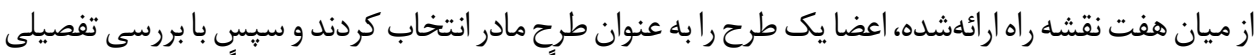

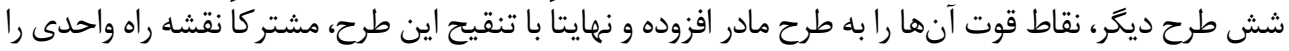

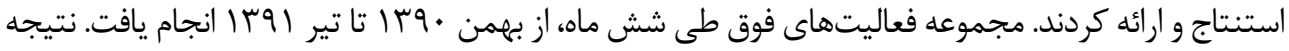

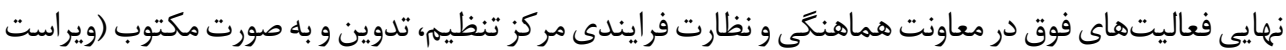

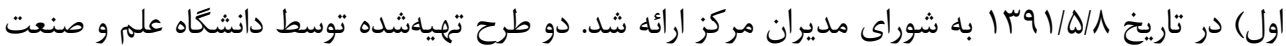

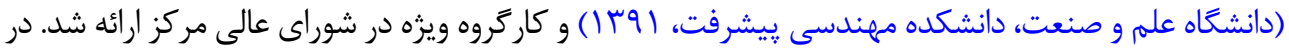

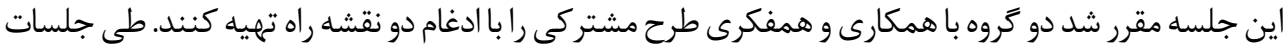

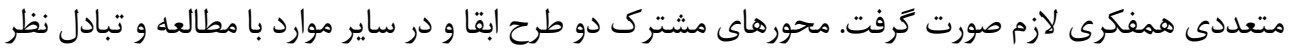

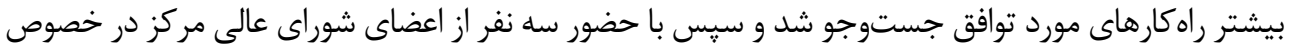

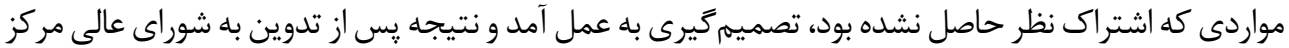

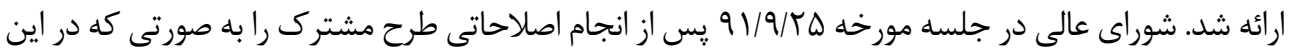
مجموعه ملاحظه مىفرماييد تصويب كرد.

به منظور تدوين لانقشه راه براى تحقيق و تدوين الكوى اسلامىايرانى ييشرفته، علاوه بر برگزارى نخستين

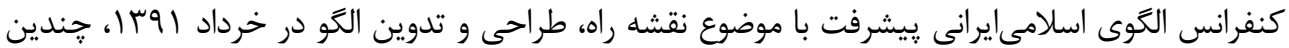

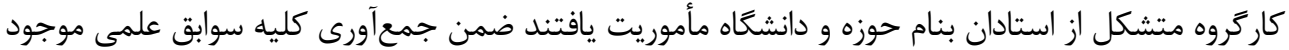

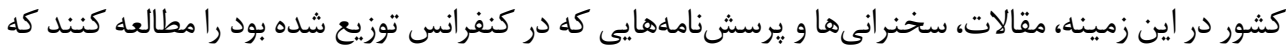

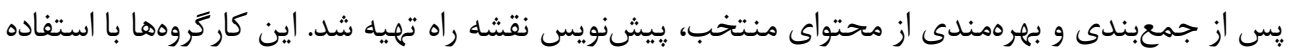

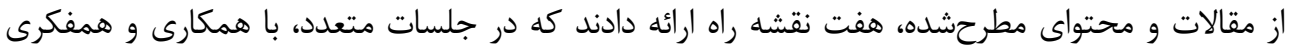

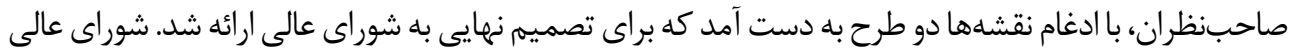

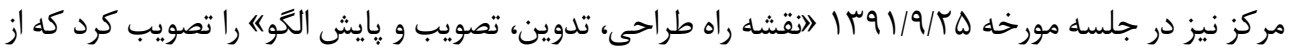

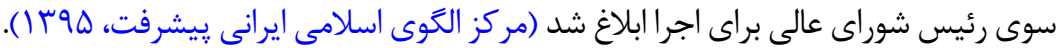

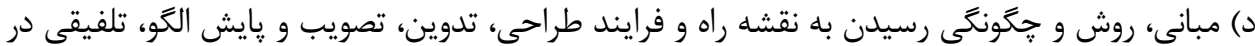
هالهاى از ابهام است؟ مبات در تبيين سؤال و اشكال مطروحه در بند "ده، با توجه به تأكيد بر "روش علمى" و اينكه روش تدوين الكو

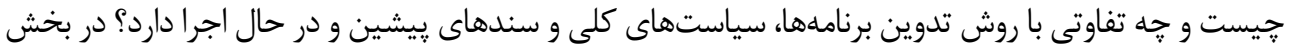

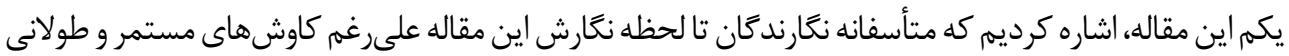


به نسخهاى كه حاوى تبيينى از روش علمى مذكوردر سند منتشره باشد، دست نيافتند و باعنايت به مطالب مذكور

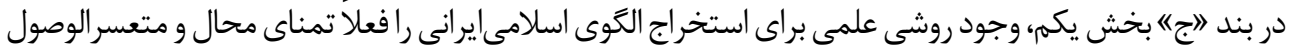

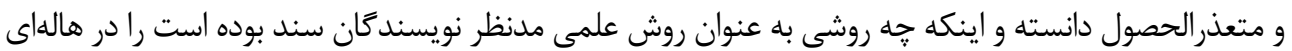

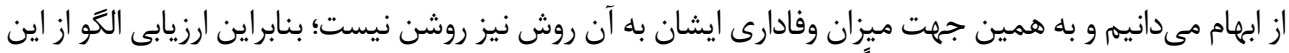

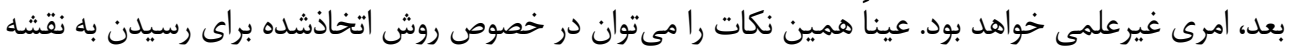

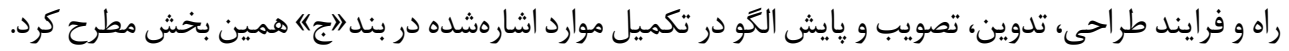

هـ) مشخص نيست كه متن منتشره مى خواهد نقشه راه برنامه باشد و يا نقشه راهى براى تهيه برنامه.

صرفنظراز درستى يا نادرستى اين تلقى كه متن منتشره نقشه راه است، روشن نيست كه اين نقشه راه يك

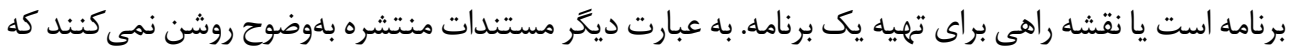

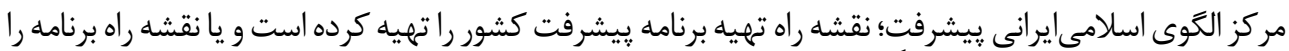

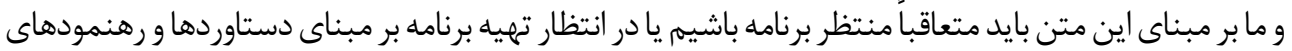

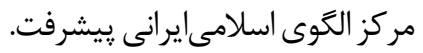

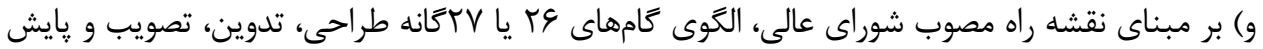

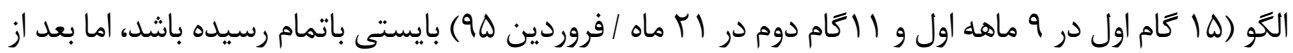

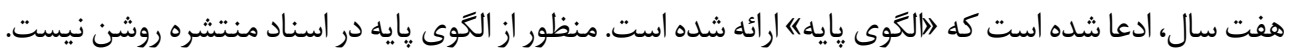

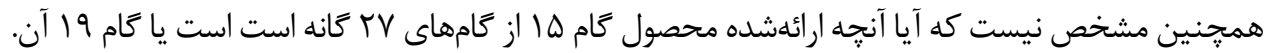

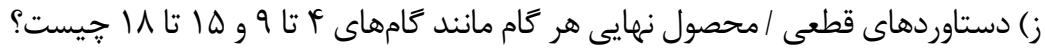
ح) در متن انتشاريافته آمده است: السند اهمّ مبانى و آرمانهاى ييشرفت را تدوين كرده ..."ا؛ بنابراين الخو به

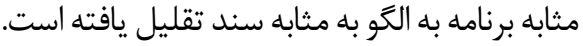

ط) در متن انتشاريافته آمده است: السند اهمّ مبانى و آرمانهاى ي ريشرفت را تدوين كرده و افُق مطلوب كشور

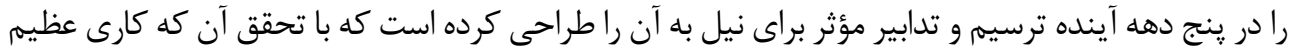

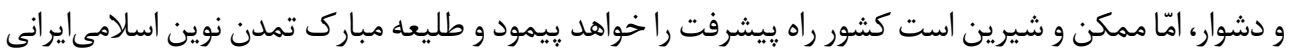

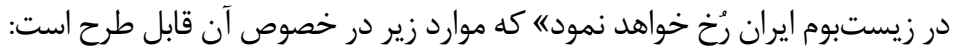

ا. در باب ترتب منطقى مبانى، آرمان ها، افق مطلوب و تدابير سخنى كفته نشده است و معلوم نيست كه جگكَونه

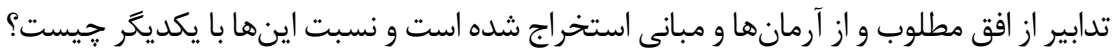

ז. منظور از اطراحى" در عبارت مذكور به غير از ذكر مواردى تحت اين عنوان در متن منتتشره است؟ ى) كلى و تفسيربردار بودن برخى بندهاى سند منتشره. ك) عدم وجود / روشن نبودن /صحيح نبودن رابطه / روابط علّى و معلولى. 
ل) با ثبات در نظر كرفتن شرايط و عدم توجه به تغييرات و تحولات و سرعت آن در • له سال آينده در هنعام تدوين سند و ارائه سندى ايستا. م) در نظر نغرفتن نظام بوركراتيك ضعيف و فاسد و ناتوان براى اجراى سند. ن) آرمان كرايى مفرط و عدم توجه به محدوديتها نظير كميابى / هزينهفرصت وضرورت انتخاب و اولويتبندى س) فقدان ضمانت اجرا.

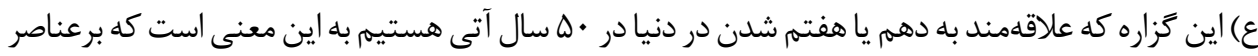

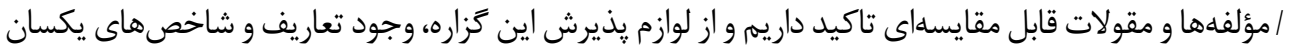

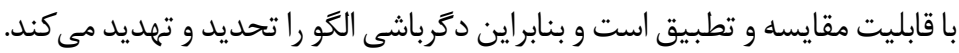

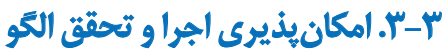

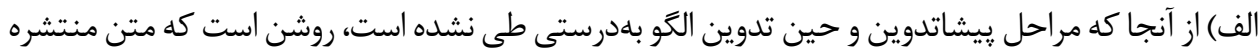

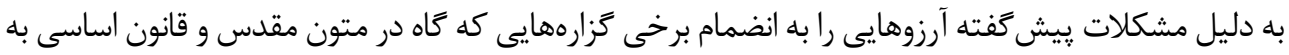

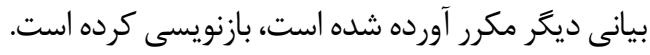

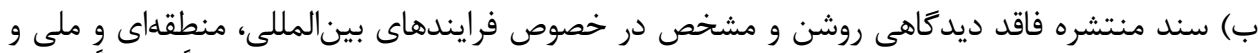

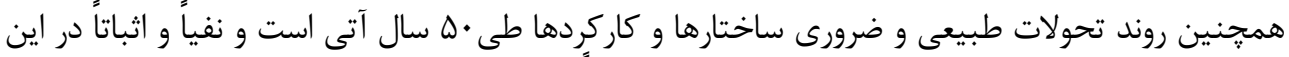

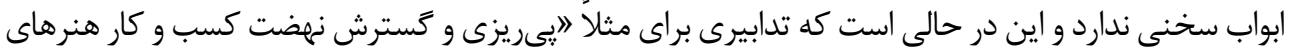

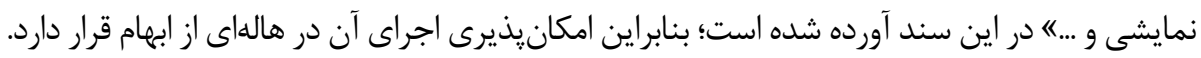

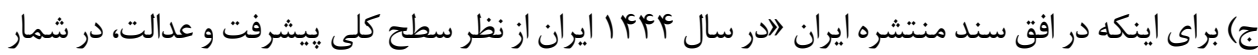

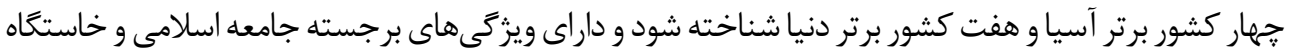

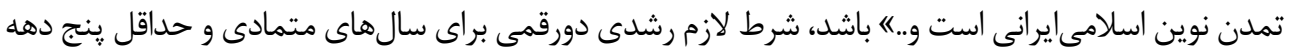

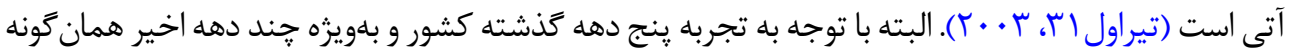

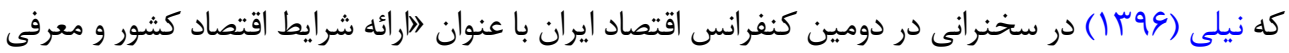

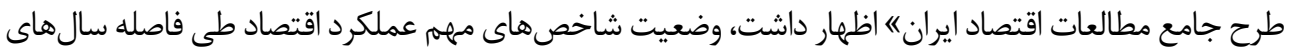

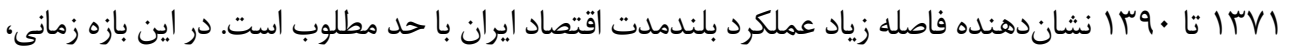

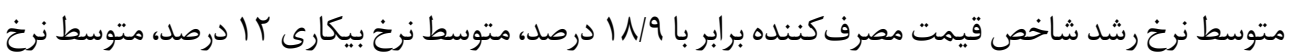

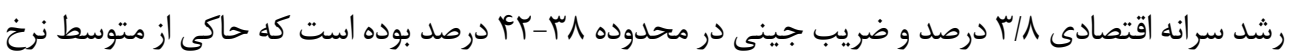

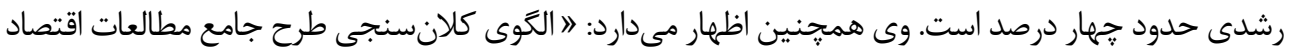

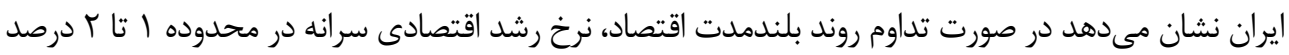




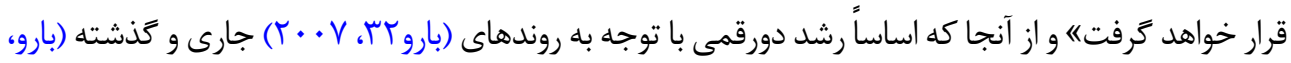

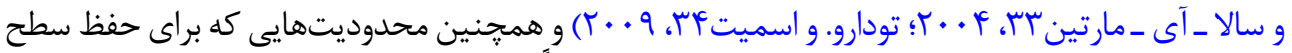

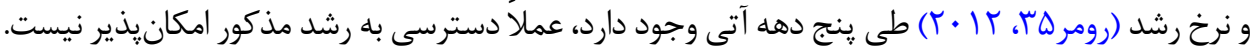
د) جه كسى يا كسانى مى توانند الكو را اجرا، عملى و محقق كنند؟ به دليل ناتوانى نظام اجتماعى و فرهنگَى و

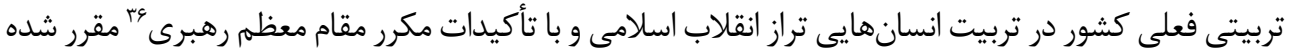

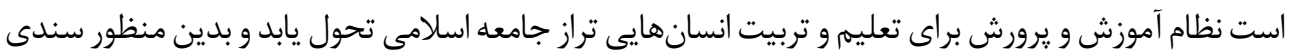

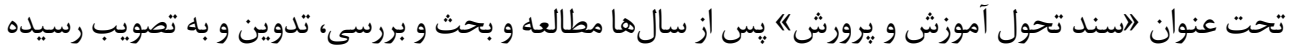

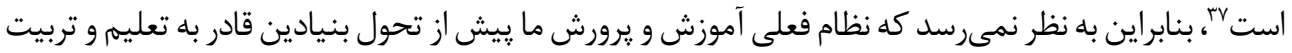

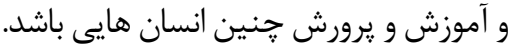

هـ) نقش نسل آتى و جوانان در اين سند منفعل است يا فعال؟ آر بيذيزيم كه نقش و جايگًاه آنها در اين سند

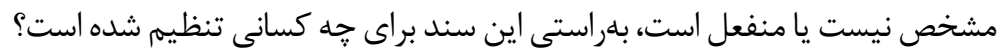

و) سازوكار تجديد نظر و حك و اصلاح و روزآمد كردن سند به طور شفاف و معلوم مشخص نيست؟ ز) يكى از مشكلات ديخر اين سند، عدم توجه به الزامات تحقق سند است كه به برخى از آنها اشاره كرديم. ح) يكى از مشكلات كشور ما تراكم قوانين، اسناد، سياستهاو مقررات است. ط) وجود اسناد و برنامههاى ديخر با اولويت بالاتر. ى) فقدان نظام انخيزشى در سند. ك) عدم توجه به تغييرات و تحولات شتابان و روند ير فرازونشيب آنها. ل) موانع و نارسايى هاى ساختارى ـ كاركردى تهيه و اجر ايیى برنامهها و ناكار آمدى روزافزون نظام اجرايى كشور. م) عدم توجه به تحول مفاهيم در طى زمان.

\section{Barro}

33. Barro \& Sala-i-Martin

34. Todaro \& Smith

35. Romer

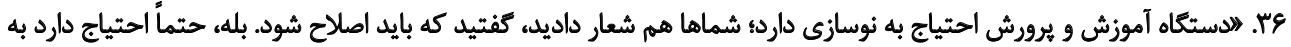

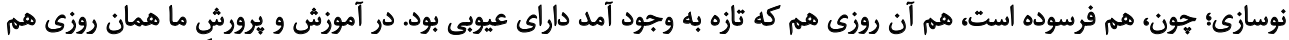

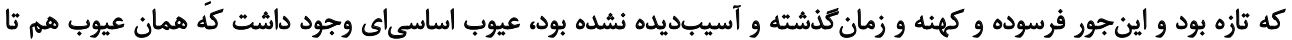

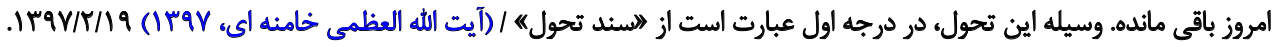

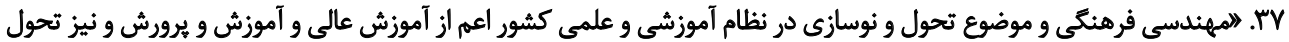

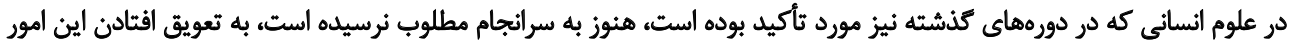

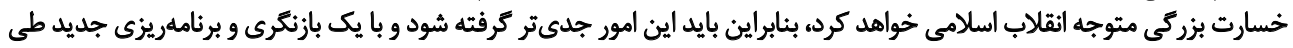

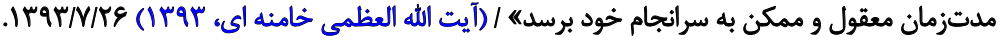




\section{ع. بحث و نتيجلَّيرى}

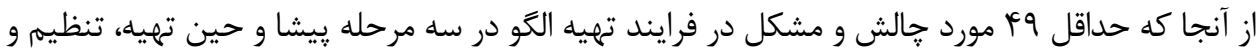

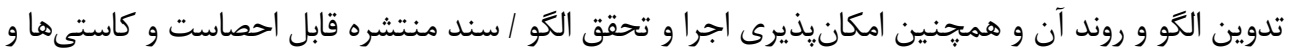

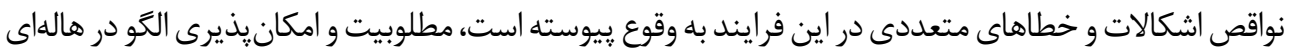

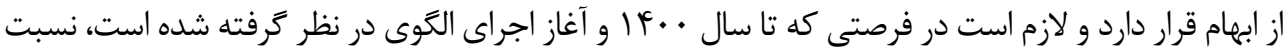

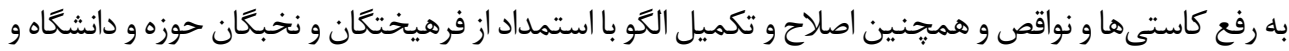

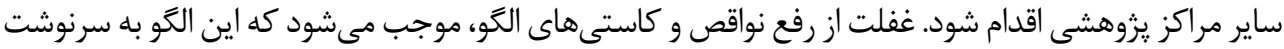

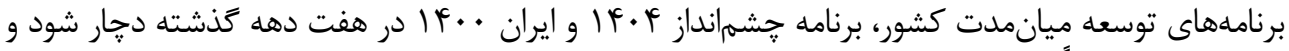

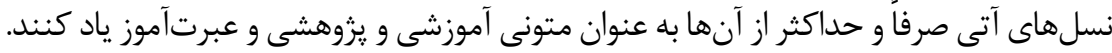

ملاحظات اخلاقي

\section{يبيروى از الصول الخلاق يثروهش}

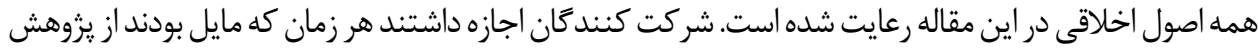

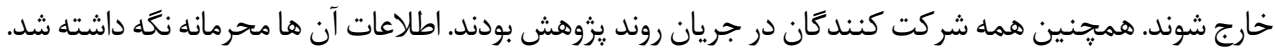

حامي مالي

اين يزوهش هيجِّونه كمك مالى از سازمانيهاى دولتى، خصوصى و غيرانتفاعى دريافت نكرده است.

مشاركت نويسند

تمام نويسندكان در آمادهازى اين مقاله مشاركت داشتهاند.

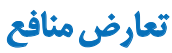

بنابر اظهار نويسندًان، اين مقاله تعارض منافع ندارد. 


\section{References}

Aarabi, S. M. (2013). [Process and outcome patterns in the Islamic Iranian model of progress (Persian)]. In Deputy for Planning for the Development of the Islamic Iranian Model of Progress (Ed). Discourses on the basics, concepts and methodology of the Islamic Iranian model of progress. Tehran: Vice President for Strategic Planning and Oversight. http://opac.nlai.ir/opac-prod/ bibliographic/2977228

Aliahmadi, A. R. (2011). [Sketsh of Islamic Iranian of progress pattern (Persian)]. Tehran: Tolide Danesh. http://opac.nlai.ir/opac$\mathrm{prod} /$ bibliographic/2319104

Barro, R. J., \& Sala-i-Martin, X. (2004). Economic growth. Cambridge: MIT Press. https://books.google.com/books?id=jD3ASoSQJ-AC\&dq

Barro, R. (2007). Macroeconomics: A modern approach. Boston: Cengage Learning. https://books.google.com/books?id=g_y0eJLbDA4C\&dq

Center for the Islamic Iranian Model of Progress. (2015). [The draft documents of the basic Iranian Islamic model of progress were reviewed (Persian)]. Tehran: Center for the Islamic Iranian Model of Progress. http://nashr.olgou.ir/sites/default/files/ mahnameh/K-29.pdf

Center for the Islamic Iranian Model of Progress. (2012). [What is the meaning and concept of the Islamic Iranian model of progress and road map and design process, editing, approval, and monitor of the model (Persian)]. Tehran: Center for the Islamic Iranian Model of Progress. http://www.olgou.ir/downloads/roadmap/Finalmap.pdf

Center for the Islamic Iranian Model of Progress. (2016). [Introduction to Center for the Islamic Iranian Model of Progress (Persian)]. Retrieved from http://nashr.olgou.ir/sites/default/files/mahnameh/Ashenaei\%20ba\%20Markaz.pdf

Elahi, A. (2018). [Some of the main challenges of the Islamic Iranian model of progress document (Persian)]. Retrieved from https://www.mehrnews.com/news/4597033/

Farabi, M. I. M. (1986). [The opinions of the people of the utopia (Arabic)]. Beirut: Dar al-Mashregh. https://www.noorlib.ir/View/ fa/Book/BookView/Image/58176

Gholami, R. (2018). [Islamic Iranian basic pattern, what is, what to do (Persian)]. Sadra, (26-27), 211-14. https://bit.ly/3fPl4Vs

Hemmati, H. (2019). [The minimal approach of the progress model document to Islamic jurisprudence / the need to pay attention to the sys-tematizing capacity of Shiite jurisprudence (Persian)]. Retrieved from https:/iqna.ir/fa/news/3777948/

Ibn Abi Shibat, A. I. M. (2008). [Classified in hadiths and monuments (mosnaf Ibn Abi Shibat fi al-ahadith va al-asar) (Arabic)]. Vol. 8. Beirut: Dar al-Fekr li al-Tebaat va al-Nashr va al-Tooziee. https://www.noorlib.ir/View/fa/Book/BookView/Image $/ 27673$

Ibn Shahr Ashoob, M. I. A. (2010). [Virtues of Abi Talib family (managheb ala Abi Talib) (Arabic)]. Vol. 1. Qom: Al-Maktab al-Heydariyah. https:/www.noorlib.ir/View/fa/Book/BookView/Image/20242

Iran University of Science and Technology, the School of Progress Engineering. (2012). [Proposed roadmap for achieving the Islamic-Iranian model of progress (Persian)]. Retrieved from Not Found Link

Izadhi, S. S. (2018). [The current text is crude and in some paragraphs is not of the pattern of progress / the two main objectives of the leadership call to complete the basic document (Persian)]. Retrieved from https://iqna.ir/fa/news/3763921/

Jami, A. I. A. (1987). [Seven throne (haft awrang) (Persian)]. Modarres Gilani, M., Ed. Tehran: Saadi. https:/lib1.ut.ac.ir:8443/ site/catalogue/1037799 
Keshvari, A. (2018). [We have 9 remarks about the proposed document of the basic model of progress / The model of citing this document to Islam is not known (Persian)]. Retrieved from https://pishraft-varamin1.blog.ir/1397/09/01/

Khamenei, S. A. (2018). [The call of leader of the revolution to complete and promote the basic Iranian Islamic model of progress (Persian)]. Retrieved from https://farsi.khamenei.ir/news-content?id=40693

Khamenei, S. A. (1991-2018). [Statement archive (Persian)]. Retrieved from https://farsi.khamenei.ir/speech

Khomini, R. (2006). [Sahifa Imam Khomini (scripture of Imam Khomini) (Persian)]. Tehran: Imam Khomeini Publishing House. http://opac.nlai.ir/opac-prod/bibliographic/1025440

Lakzaee, Sh. (2019). [The basic document of the model of progress lacks philosophical support / the content of the meetings of the think tanks is not reflected much in the text (Persian)]. Retrieved from https://iqna.ir/fa/news/3759933/

Nasir al-Din al-Tusi, M. I. M. (1981). [Nasirean ethics (Akhlagh-e Naseri) (Persian)]. Minavi, M., \& Heidari, A. R., Eds. Tehran: Kharazmi. https://lib1.ut.ac.ir:8443/site/catalogue/862432

Nili, M. (2017). [Presenting the economic conditions of the country and introducing the comprehensive plan of Iranian economic studies (Persian)]. Paper presented at $2^{\text {nd }}$ Iranian Economic Conference, Rayzan International Conference Centre, Tehran, Iran, 16 December 2017. http://conference.imps.ac.ir/cie/Default.aspx?PageName=News\&ID=190\&Language=1\&title=

Nobakht, M. B. (2010). [Optimal model of Iranian Islamic development (Persian)]. In Center for the Islamic Iranian Model of Progress (Ed). The first meeting of strategic ideas (pp. 237-51). Tehran: Center for the Islamic Iranian Model of Progress. https://bit.ly/2Bhembq

Mohammadi, J. (2018). [A critique of the document of the Iranian-Islamic model of progress (Persian)]. Retrieved from https:// www.asriran.com/fa/news/635916/

Quran. (2020). [An-Nahl, ayah: 112 (Arabic-Persian)]. Retrieved from http://www.parsquran.com/data/show.php?lang=far\&sura $=16 \&$ ayat $=0 \&$ user $=$ far\&tran $=1$

Quran. (2020). [Al-Qasas, ayah: 5 (Arabic-Persian)]. Retrieved from http://www.parsquran.com/data/show.php?user=far\&lang=far\&ayat $=1 \&$ sura $=28$

Quran. (2020). [Al-Mumtahanah, ayahs: 4 \& 6 (Arabic-Persian)]. Retrieved from http://www.parsquran.com/data/show.php?user=far\&lang=far\&ayat $=1 \&$ sura $=60$

Rashad, A. A. (2012). [Nine steps to the pattern of Islamic Iranian Islamic progress (the roadmap for exploring the epistemological foundations of the value of progress and designing the Islamic Iranian model of progress) (Persian)]. In Center for the Islamic Iranian Model of Progress (Ed). Roadmap for editing and designing the Islamic Iranian model of progress (pp. 44-7). Tehran: Center for the Islamic Iranian Model of Progress. http://nashr.olgou.ir/sites/default/files/mahnameh/1\%20a.pdf

Romer, D. (2012). Advanced macroeconomics. $4^{\text {th }}$ Ed. New York: McGraw-Hill Education. https://www.mheducation.com/ highered/product/advanced-macroeconomics-romer/M9780073511375.html

Sadr al-Din Shirazi, M. I. E. (1975). [Principle and Akhirah (al-Mabdae va al-Maad) (Arabic)]. Tehran: Iranian Philosophical Society. https://www.noorlib.ir/view/fa/book/bookview/text/11706

Strategic Council Model of Islamic Progress. (2011). [Roadmap for producing a model of Islamic progress - the stage of creation (Persian)]. Retrieved from https://bit.ly/311uRDD

Tabarsi, F. I. H. (1991). [Interpretation of collector societies (tafsir jawamie al-jamie) (Persian)]. Gorji, A., Ed. Tehran: Tehran University Press. https://ib1.ut.ac.ir:8443/site/catalogue/2182 
Thirlwall, A. P. (2003). Growth and development: With special reference to developing economies. $7^{\text {th }}$ Ed. London: Palgrave Macmillan. https://books.google.com/books?id=O4a2QgAACAAJ\&dq

Todaro, M. P., \& Smith, S. C. (2009). Economic development. 10 ${ }^{\text {th }}$ Ed. Boston: Pearson Education Limited. https://books.google com/books?id=VODtAAAAMAAJ\&dq

Zoelm, A. (2012). [Roadmap for designing the Islamic Iranian model of progress (Persian)]. In Center for the Islamic Iranian Model of Progress (Ed). Roadmap for editing and designing the Islamic Iranian model of progress (pp. 92-105). Tehran: Center for the Islamic Iranian Model of Progress. http://nashr.olgou.ir/sites/default/files/mahnameh/1\%20a.pdf 